OPEN ACCESS

Edited by:

Atsushi J. Nagano,

Ryukoku University,

Japan

Reviewed by:

Bin Han

Chinese Academy of Agricultural

Sciences, China

Rikard Fristedt,

Vrije Universiteit Amsterdam,

Netherlands

*Correspondence:

Shizue Matsubara

s.matsubara@fz-juelich.de

Pitter F. Huesgen

p.huesgen@fz-juelich.de

${ }^{\dagger}$ Present address:

Trang Schneider,

KWS LOCHOW GmbH,

Bergen, Germany

Specialty section:

This article was submitted to

Evolutionary and

Population Genetics,

a section of the journal

Frontiers in Genetics

Received: 14 October 2019

Accepted: 10 February 2020

Published: 05 March 2020

Citation:

Niedermaier S, Schneider T,

Bahl M-O, Matsubara S and

Huesgen PF (2020) Photoprotective

Acclimation of the Arabidopsis thaliana

Leaf Proteome to Fluctuating Light.

Front. Genet. 11:154.

doi: 10.3389/fgene.2020.00154

\section{Photoprotective Acclimation of the Arabidopsis thaliana Leaf Proteome to Fluctuating Light}

\author{
Stefan Niedermaier ${ }^{1}$, Trang Schneider ${ }^{2,3 \dagger}$, Marc-Oliver Bahl ${ }^{2}$, Shizue Matsubara ${ }^{2 *}$ \\ and Pitter F. Huesgen ${ }^{1,4 *}$ \\ 1 ZEA-3 Analytics, Forschungszentrum Jülich, Jülich, Germany, ${ }^{2}$ IBG-2 Plant Sciences, Forschungszentrum Jülich, Jülich, \\ Germany, ${ }^{3}$ iGRAD-Plant, Department of Biology, Heinrich Heine University Düsseldorf, Düsseldorf, Germany, ${ }^{4}$ Cologne \\ Excellence Cluster on Cellular Stress Responses in Aging Associated Diseases (CECAD), Medical Faculty and University \\ Hospital, University of Cologne, Cologne, Germany
}

Plants are subjected to strong fluctuations in light intensity in their natural growth environment, caused both by unpredictable changes due to weather conditions and movement of clouds and upper canopy leaves and predictable changes during day-night cycle. The mechanisms of long-term acclimation to fluctuating light (FL) are still not well understood. Here, we used quantitative mass spectrometry to investigate long-term acclimation of low light-grown Arabidopsis thaliana to a FL condition that induces mild photooxidative stress. On the third day of exposure to FL, young and mature leaves were harvested in the morning and at the end of day for proteome analysis using a stable isotope labeling approach. We identified 2,313 proteins, out of which 559 proteins exhibited significant changes in abundance in at least one of the four experimental groups (morning-young, morning-mature, end-of-day-young, end-of-day-mature). A core set of 49 proteins showed significant responses to FL in three or four experimental groups, which included enhanced accumulation of proteins involved in photoprotection, cyclic electron flow around photosystem I, photorespiration, and glycolysis, while specific glutathione transferases and proteins involved in translation and chlorophyll biosynthesis were reduced in abundance. In addition, we observed pathway- and protein-specific changes predominantly at the end of day, whereas few changes were observed exclusively in the morning. Comparison of the proteome data with the matching transcript data revealed gene- and protein-specific responses, with several chloroplastlocalized proteins decreasing in abundance despite increased gene expression under FL. Together, our data shows moderate but widespread alterations of protein abundance during acclimation to FL and suggests an important role of post-transcriptional regulation of protein abundance.

Keywords: acclimation, fluctuating light, leaf proteome, photooxidative stress, photoprotection, protein turnover, time of day, quantitative proteomics 


\section{INTRODUCTION}

Earth's terrestrial environment is highly dynamic and variable, with daily and seasonal changes in factors that affect plant life, such as light, temperature, and rainfall. Of all the environmental factors, light is the one that changes most rapidly and frequently due to Earth's rotation, weather conditions, cloud movement, and foliage motion in the wind (swaying, fluttering). Oxygenic photosynthesis_ - the type of photosynthesis which uses water as the electron donor and produces $\mathrm{O}_{2}$ as a byproduct-must operate with this very erratic power supply which fluctuates between energy shortage and energy overload.

Plants have evolved manifold mechanisms to balance energy and electron supply and demand during light fluctuations. In a short term, for example, the supply-demand imbalance results in acidification of thylakoid lumen which triggers thermal dissipation of absorbed light energy (or non-photochemical quenching, NPQ) in light harvesting antenna complexes of photosystem II (PSII) via PsbS protein protonation ( $\mathrm{Li}$ et al., 2004) and activation of violaxanthin de-epoxidase (Hager and Holocher, 1994). Low lumenal $\mathrm{pH}$ also downregulates electron transport by slowing down plastoquinol reoxidation of cytochrome $b_{6} f$ (Takizawa et al., 2007). On the acceptor side of photosystem I (PSI), excess electrons can be transferred from ferredoxin back to plastoquinone by cyclic electron flow (CEF) involving PGR5 (proton gradient regulation 5; Munekage et al., 2002) or NADH dehydrogenase (NDH)-like complex (Shikanai et al., 1998), thereby pumping $\mathrm{H}^{+}$from chloroplast stroma into the lumen at cytochrome $\mathrm{b}_{6} \mathrm{f}$ and $\mathrm{NDH}$-like complex without synthesizing NADPH. Chloroplasts also have various enzymatic and non-enzymatic antioxidants which detoxify reactive oxygen species (ROS) generated by inevitable transfer of excess light energy and excess electrons to $\mathrm{O}_{2}$ (Noctor and Foyer, 1998; Asada, 1999; Asensi-Fabado and Munne-Bosch, 2010). Even though these and other mechanisms are operating to protect the photosynthetic apparatus against excess light and photooxidation, PSII reaction center, the D1 protein in particular, is prone to photoinactivation and photodamage not only under excess light but also under low light (Anderson et al., 1997). Damaged PSII reaction centers are continuously repaired through intricate multi-step processes of disassembly, degradation of damaged D1 and insertion of newly synthesized D1 followed by reassembly to maintain the PSII activity and minimize chronic photoinhibition (Jarvi et al., 2015; Theis and Schroda, 2016). Since the repair of PSII is also sensitive to ROS, which inhibits D1 protein synthesis (Nishiyama et al., 2004), it is essential to keep ROS under control.

In a long term, acclimation to growth light environment alters a range of plant traits, from biochemical composition to morphology and architecture (Poorter et al., 2019), which together enhance plant performance and fitness. Some of the components of short-term mechanisms described above are known to be increased or decreased during long-term photoacclimation. Typically, accumulation of PSII light harvesting antenna complexes is increased under low light to compensate for limited light energy supply, whereas cytochrome $\mathrm{b}_{6} \mathrm{f}$ and ATP synthase are more abundant in high light to boost electron transport and ATP production (Anderson et al., 1988; Walters, 2005; Schottler and Toth, 2014). Leaves in high light also contain larger pools of antioxidants and have increased capacities for photoprotection and D1 repair (Aro et al., 1993; Grace and Logan, 1996; Demmig-Adams, 1998). Despite the wealth of knowledge about the phenotypic outputs of long-term photoacclimation, the molecular mechanisms, which control these variations, are elusive and we know little about how they are coordinated at different levels and time scales (Dietz, 2015).

Most laboratory experiments of long-term acclimation are conducted under non-fluctuating constant light (CL) conditions, even though these conditions differ greatly from highly variable natural light environments (Annunziata et al., 2017; Matsubara, 2018). So far, only a small number of studies have investigated the mechanisms of long-term acclimation to fluctuating light (FL) (Yin and Johnson, 2000; Alter et al., 2012; Annunziata et al., 2017; Vialet-Chabrand et al., 2017; Kaiser et al., 2018; Matsubara, 2018; Schneider et al., 2019). In order to gain a systems-level overview of long-term acclimatory changes happening in FL conditions, we recently studied global reprogramming of gene expression in young and mature leaves of low-light grown Arabidopsis plants after 3-d exposure to a highly dynamic FL regime (Schneider et al., 2019). Long-term acclimation to this kind of FL conditions, that are characterized by repetitive exposure to brief and strong light pulses ("lightflecks") in otherwise light-limited environment, enhances NPQ and ROS scavenging capacities in Arabidopsis leaves while repressing PSII electron transport, sugar and starch accumulation, as well as growth (Alter et al., 2012; Schneider et al., 2019). The transcriptomic changes observed under the FL condition included, among others, upregulation of many genes involved in photosynthesis, photoprotection and photorespiration, or metabolism of antioxidants, pigments, prenylquinones, and lipids (Schneider et al., 2019). Importantly, the FL response of gene expression differed between young and mature leaves or in the same leaves between morning and the end of day, highlighting a strong influence of leaf development and time of day on long-term acclimation at the gene expression level. While the changes in gene expression were largely consistent with the phenotypic alterations observed under the FL condition (Schneider et al., 2019), long-term acclimation may also involve post-transcriptional mechanisms to adjust protein levels and composition. Identification of such posttranscriptional mechanisms may open up new possibilities to improve plant productivity in FL environments (Ort et al., 2015).

Thus, we performed a quantitative proteome analysis of young and mature leaves harvested in the morning and at the end of day under the same FL and CL conditions as in the transcriptome study by Schneider et al. (2019). Specifically, we asked the following questions: to what extent are changes in gene expression matched by corresponding changes in protein abundance during FL acclimation, and whether acclimatory adjustment of proteome is also dynamic, differing between young and mature leaves or between morning and at the end of day. 


\section{METHODS}

\section{Plant Materials and Growth Conditions}

The plant materials used in this study were harvested in the same experiments with identical growth conditions and light treatments as in the gene expression and phenotype study (Schneider et al., 2019). Briefly, seeds of Arabidopsis thaliana Columbia-0 (Col-0) were sown on moist soil (Pikier; Balster Einheitserdewerk; Fröndenberg, Germany) and incubated at $5^{\circ} \mathrm{C}$ in the dark. After 4 days, they were transferred to a climate chamber with a $12 \mathrm{~h} / 12 \mathrm{~h}$ light/dark cycle and $23^{\circ} \mathrm{C} / 18^{\circ} \mathrm{C}$ air temperature at $60 \%$ relative humidity. The intensity of photosynthetically active radiation provided by fluorescent tubes (Fluora L36 W/77; Osram, Munich, Germany) was approx. $75 \mu \mathrm{mol}$ photons $\mathrm{m}^{-2} \mathrm{~s}^{-1}$ (constant light, CL). After two weeks, seedlings were transferred to larger pots $(7 \times 7 \times 8$ $\mathrm{cm}$, one plant per pot) filled with soil (type ED 73; Balster Einheitserdewerk). After 2 to 3 more weeks of cultivation in the CL condition, plants were divided into two groups: a control group, which remained in the CL condition, and a treatment group, which was exposed to FL in which the light intensity was changing between $\sim 75 \mu \mathrm{mol}$ photons $\mathrm{m}^{-2} \mathrm{~s}^{-1}$ (the CL background) and $\sim 1,000 \mu \mathrm{mol}$ photons $\mathrm{m}^{-2} \mathrm{~s}^{-1}$ in the same climate chamber. The high light pulses (ca. $20 \mathrm{~s}$ duration) of the FL treatment were applied every $5 \mathrm{~min}$ by using white LEDs (IP65, as-Schwabe, Eutingen, Germany) which were moving over the plants during the light period, as described previously (Alter et al., 2012). The light spectra of fluorescent tubes (CL) and white LEDs (high light pulses of FL) measured in the climate chamber using SpectraPen mini (Photon Systems Instruments, Drásov, Czech Republic) are shown in Supplementary Figure 1. Young and mature leaves were separately harvested from five individual plants $(\mathrm{n}=5)$ in the morning ( $1 \mathrm{~h}$ after the light was turned on) and at the end of day ( $1 \mathrm{~h}$ before the light was turned off) on the third day of the FL or CL treatment as described by Schneider et al. (2019). Leaves were shock-frozen in liquid nitrogen and stored at $-80^{\circ} \mathrm{C}$ until protein extraction.

\section{Sample Preparation}

Samples were prepared by using our leaf extraction protocol for protein N-termini profiling in complex samples (Demir et al., 2017) with some modifications for shotgun proteomics. Frozen leaf samples were transferred into $5 \mathrm{ml}$ reaction tubes and homogenized with $1.5 \mathrm{ml}$ protein extraction buffer $(150 \mathrm{mM}$ HEPES, $6 \mathrm{M} \mathrm{GuHCl}$, and $5 \mathrm{mM}$ EDTA, pH 7.5 adjusted with $1 \mathrm{M}$ $\mathrm{NaOH})$ and added HALT Protease Inhibitor Cocktail (1:100, Thermo Fisher Scientific) using a KINEAMTICA Polytron at approx. $30.000 \mathrm{rpm}$ for $1 \mathrm{~min}$. The resulting suspension was filtered through a Miracloth mesh, the flow-through was collected and centrifuged for $10 \mathrm{~min}$ at $500 \times \mathrm{g}$ and $4^{\circ} \mathrm{C}$ and 1 $\mathrm{ml}$ of the supernatant was transferred to fresh $2 \mathrm{ml}$ reaction tubes. A sample of $200 \mu \mathrm{l}$ was precipitated using chloroform/ methanol precipitation (Wessel and Flügge, 1984), washed twice with $1 \mathrm{ml}$ ice-cold $\mathrm{MeOH}$ and dried at room temperature for 30 min before re-suspending in $200 \mu$ l protein extraction buffer. Twenty-five $\mu$ of each sample were taken to estimate protein concentration by BCA Protein Assay (Thermo Fisher Scientific) and also to verify intactness of proteome by visualizing on silverstained SDS-PAGE (Laemmli, 1970; Blum et al., 1987). Cysteine residues were carbamidomethylated by adding $10 \mathrm{mM}$ DTT for $1 \mathrm{~h}$ at $55^{\circ} \mathrm{C}$, followed by $30 \mathrm{mM}$ IAA for $30 \mathrm{~min}$ at $20^{\circ} \mathrm{C}$ in the dark and $15 \mathrm{mM}$ DTT for $20 \mathrm{~min}$ at $37^{\circ} \mathrm{C}$. Samples were precipitated again using chloroform/methanol, re-suspended in $100 \mathrm{mM}$ HEPES $\mathrm{pH} 8.0$ to a protein concentration of approx. 1 $\mathrm{mg} / \mathrm{ml}$ based on the measurement results of the BCA assay and digested with trypsin at a protease:protein ratio of $1: 100$ at $37^{\circ} \mathrm{C}$ for $16 \mathrm{~h}$. The efficiency of trypsin digestion was verified by silverstained SDS-PAGE, and peptides were isotopically labeled by reductive dimethylation with $40 \mathrm{mM}$ formaldehyde (standard ${ }^{12} \mathrm{CH}_{2} \mathrm{O}$ formaldehyde for $\mathrm{CL}$ samples and heavy ${ }^{13} \mathrm{CD}_{2} \mathrm{O}$ formaldehyde for $\mathrm{FL}$ samples) and $20 \mathrm{mM}$ cyanoborohydride for $90 \mathrm{~min}$ at $20^{\circ} \mathrm{C}$ (Boersema et al., 2009). The reaction was quenched for $15 \mathrm{~min}$ by adding $100 \mathrm{mM}$ TRIS pH 7.5. Subsequently, FL and CL samples were combined pairwise, resulting in five biological replicates of FL/CL comparison for every experimental group (morning-young, MY; morningmature, MM; end of day-young, EY; end of day-mature, EM). Prior to LC-MS/MS, all samples were desalted using reversedphase StageTips (Rappsilber et al., 2007).

\section{Mass Spectrometry, Protein Identification, and Quantification}

Desalted peptides (500 ng), as estimated from the initial BSA assay, were loaded onto a $\mathrm{C} 18$ reverse phase capillary trap column (Acclaim PepMap C18, $50 \mathrm{~cm}$ column length, $75 \mu \mathrm{m} \times$ $2 \mathrm{~cm}, 3 \mu \mathrm{m}$ particle size; Thermo Fisher Scientific) followed by separation on a $\mathrm{C} 18$ reverse phase analytical column (Acclaim PepMap C18, $75 \mu \mathrm{m} \times 50 \mathrm{~cm}, 2 \mu \mathrm{m}$ particle size, $100 \AA$ А Thermo Fisher Scientific) with an UltiMate3000 nano RSLC system (Thermo Fischer Scientific). Peptides were eluted with a 90min gradient from $2 \%$ to $35 \%(\mathrm{v} / \mathrm{v})$ acetonitrile in $0.1 \%$ formic acid in UPLC-grade $\mathrm{H}_{2} \mathrm{O}$ at a flow rate of $300 \mathrm{nl} \mathrm{min}{ }^{-1}$. The nano-LC system was online coupled to an Impact II highresolution quadrupole-time of flight (Q-TOF) tandem mass spectrometer (Bruker) using a CaptiveSpray nano-electrospray source (Bruker) as described (Beck et al., 2015; Weng et al., 2019). Peptides were identified, quantified, and matched to corresponding proteins using the Max-Quant software package, version 1.5.6.5. (Cox and Mann, 2008). Generic settings for Bruker Q-TOF instruments were used to match mass spectra to protein sequence in the A. thaliana Uniprot proteome database (www.uniprot.org; release 2016/11, 33463 entries). Trypsin was set as digestion protease allowing for up to two missed cleavages. The re-quantification feature of MaxQuant was enabled, "match between runs" was disabled. Lys side chains and peptide N-terminal dimethyl labeling was set according to the stable isotope reagents used $(+28.0313 \mathrm{kDa}$ for CL samples and $+34.0631 \mathrm{kDa}$ for FL samples). Carbamidomethylation of cysteines was set as fixed modification, N-terminal protein acetylation and methionine oxidation were considered as variable modifications with a maximum of five variable modifications per peptide. 


\section{Data Analysis}

The MaxQuant output file "proteingroups.txt" was loaded into Perseus software framework (Version 1.6.2.2) (Tyanova and Cox, 2018). Proteins annotated as potential contaminants, reverse hits (false positives) or only identified by modification site were removed, resulting in 2,313 identified protein groups. For each biological replicate of each experiment, protein abundance ratios (FL/CL) were $\log 2$ transformed and normalized to the median ratio of all proteins within the replicate to correct for potential differences in overall proteome abundance. Each of the four experimental groups (MY, MM, EY, EM) was filtered to select only those proteins that were quantified in at least three of the five replicates and the resulting data were imported into $\mathrm{R}$ statistical software to perform a moderated t-test using LIMMA package (Ritchie et al., 2015; Phipson et al., 2016). The results of each experimental group were reimported into Perseus, merged by Protein ID before adding Uniprot annotations (2018). Annotations of proteins and genes included in Tables 1-3 and Supplementary Tables 6, 7, and 9 were manually checked using TAIR10 gene description (https:// www.arabidopsis.org/). Proteins with a Benjamini-Hochberg false discovery rate (FDR) corrected p-value $\leq 0.05$ were considered to respond significantly to FL.

\section{GO Term Enrichment Analysis}

Gene Ontology (GO) term and KEGG pathway enrichment analysis was performed using g:Profiler (Raudvere et al., 2019) with generic settings and whole proteome $A$. thaliana background list. ATG identifiers were used to run queries. If a protein referred to more than one gene, for example ribosomal proteins, only the first gene ID was considered. Significance thresholds were calculated using the multiple-testing corrected SCS algorithm and set to 0.05 FDR. If the number of enriched
GO terms exceeded five, only the five most significant ones were shown.

\section{RESULTS}

To investigate the impact of FL on Arabidopsis leaf proteome, 4- to 5-week-old plants grown under CL intensity of $\sim 75 \mu \mathrm{mol}$ photons $\mathrm{m}^{-2} \mathrm{~s}^{-1}(12 \mathrm{~h} / 12 \mathrm{~h}$ day/night cycle) were divided into two groups: a control group that stayed under CL and the second group that was exposed to FL in the same climate chamber (Figure 1). The light intensity in FL was changing between $\sim 75$ (CL background; $~ 280 \mathrm{~s}$ ) and $\sim 1,000 \mu \mathrm{mol}$ photons $\mathrm{m}^{-2} \mathrm{~s}^{-1}(\sim 20 \mathrm{~s})$ during the light period. On the third day of the FL treatment, young and mature leaves (as defined by Schneider et al., 2019) were harvested from the plants 1 $\mathrm{h}$ (morning young, "MY" and morning mature, "MM") and $11 \mathrm{~h}$ (end of day young, "EY", and end of day mature, "EM") after the light was turned on. Note that both morning and end-of-day samples were taken during the light phase and not in the dark phase of the $12 \mathrm{~h} / 12 \mathrm{~h}$ light/dark regime. For each of the four combinations of leaf development stage $\times$ time of day (MY, MM, EY, EM), which are defined as the four different "samples" of the experiment, leaves were individually harvested from five biological replicate plants of CL and FL and immediately frozen in liquid nitrogen.

Proteins were extracted separately from each of the five biological replicates and digested with trypsin (Figure 2A). Subsequently, peptides of CL and FL were differentially labeled with stable isotope by reductive dimethylation before pairwise pooling of one FL and one CL probe of the same developmental stage and time point. Thus, there were five biological replicates of FL/CL comparison for each of the four samples (MY, MM, EY, and EM) for the proteome analysis. Spectrum to database matching identified a total of 2,313 proteins in the samples

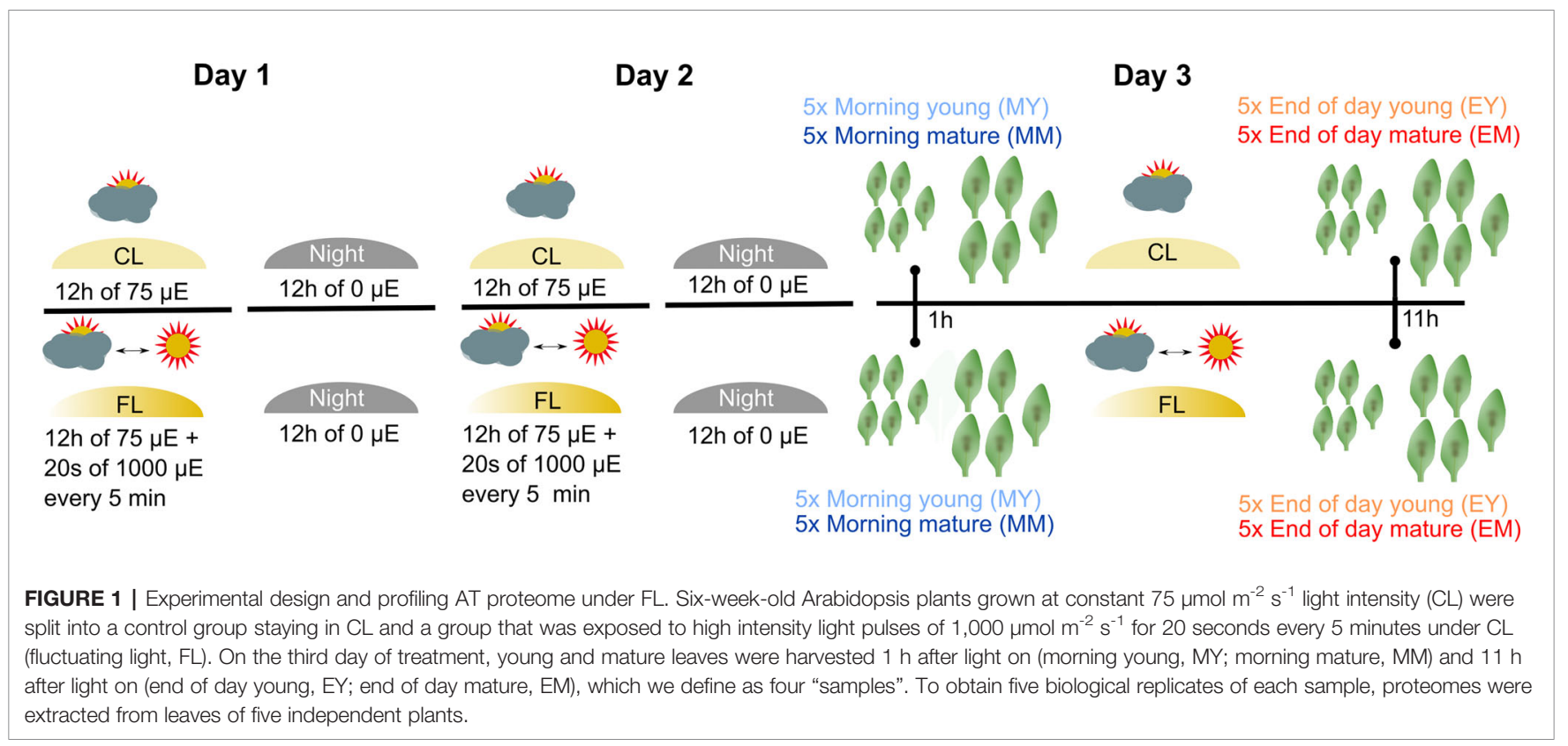


A

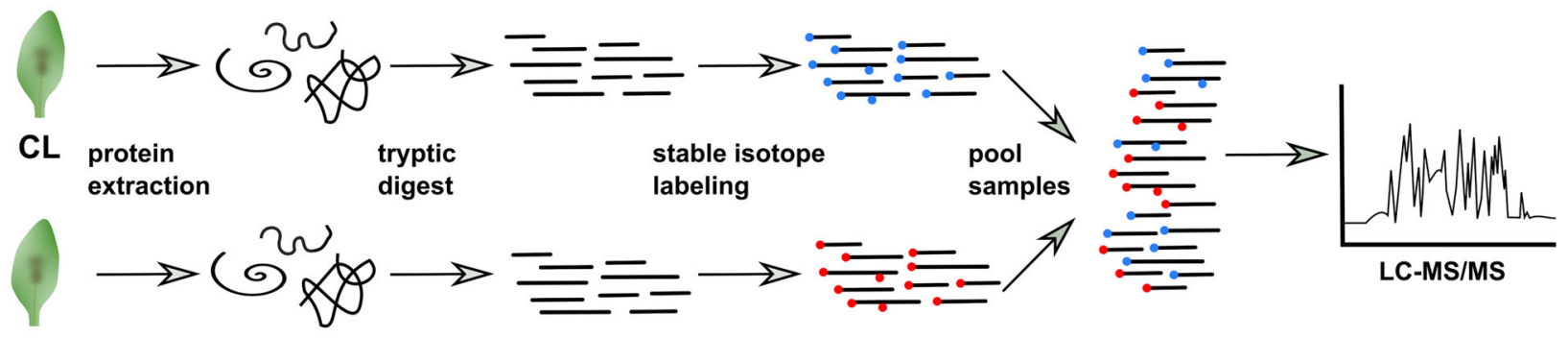

FL

B

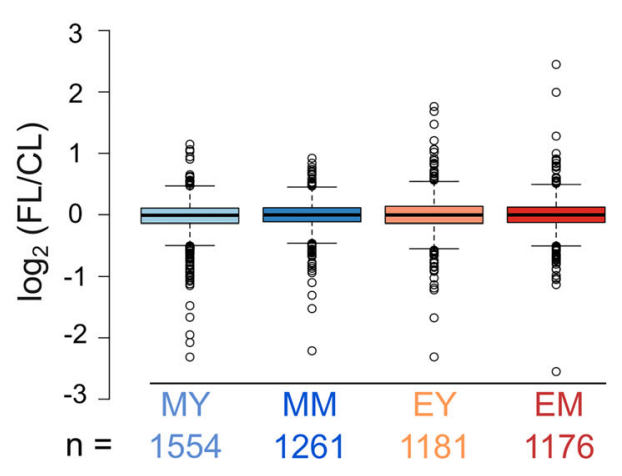

C

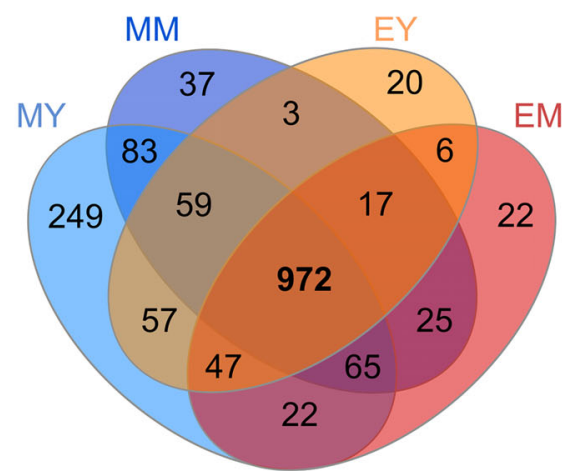

D

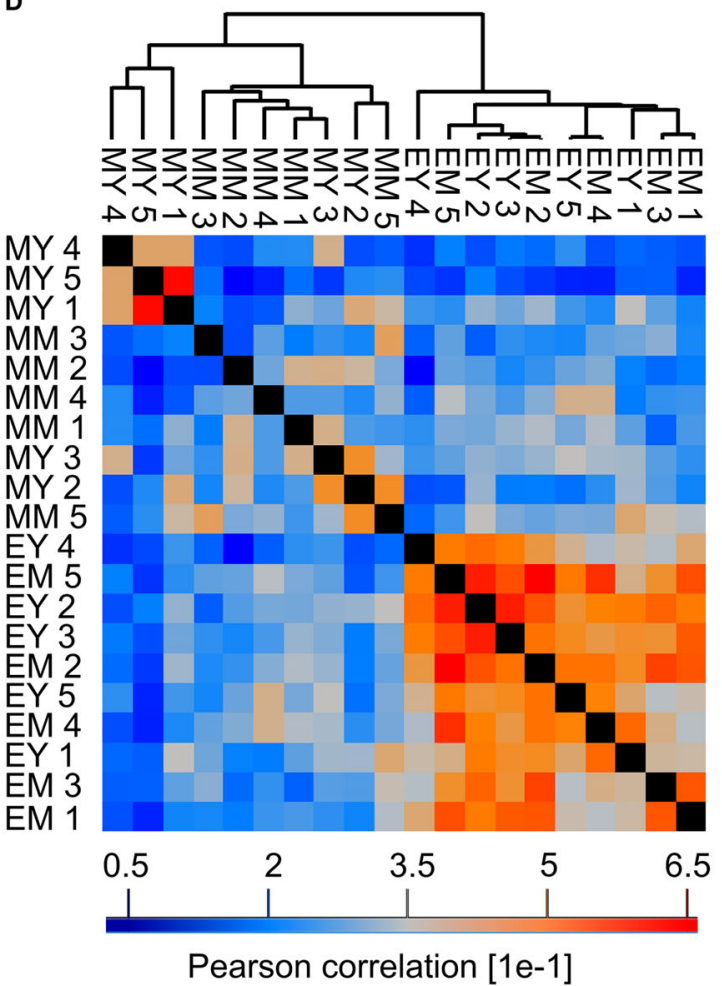

FIGURE 2 | Proteomics workflow and overview of the FL experiment dataset. (A) Proteins were extracted, digested into peptides and CL and FL samples differentially stable isotope labeled with formaldehyde reagents before randomized pairwise pooling of FL and CL proteomes for analysis by nanoLC-MS/MS. (B) Median normalized FL/CL ratios of proteins quantified in atleast three of the five biological replicates of each sample. Whiskers extend to 5th and 95th percentile. (C) Overlap of proteins quantified in at least three out of five replicates in the four samples. (D) Pearson correlation of protein ratios between the biological replicates of the 972 proteins that were quantified in at least three replicates for every sample.

(Supplementary Table 1), of which $1,554,1,261,1,181$, and 1,176 were reliably quantified in at least three out of the five biological FL/CL replicates of MY, MM, EY, and EM, respectively. At both leaf development stages and time points, FL-induced changes in protein abundance were very moderate, with more than $90 \%$ of the quantified proteins changing by less than $40 \%$ in abundance (Figure 2B). This is in line with the absence of visible stress symptoms and the relatively small changes in the transcript abundance previously found in young and mature leaves of Arabidopsis plants (Schneider et al., 2019) that were comparable with the leaves used in this study. In total, 972 proteins were reliably quantified in at least three replicates of all four samples (Figure 2C). Pearson correlation of FL/CL ratios of these 972 proteins revealed two distinct clusters among all individual replicates, namely, the morning and the end-of-day cluster, while young and mature leaves were not separated 
TABLE 1 | Proteins with significant changes in protein abundance in FL compared to CL in all samples (MY, MM, EY, and EM). Significant changes are indicated in bold numbers.

\begin{tabular}{|c|c|c|c|c|c|c|c|c|}
\hline $\begin{array}{l}\text { Majority } \\
\text { protein IDs }\end{array}$ & AGI locus & $\begin{array}{l}\text { Gene } \\
\text { names }\end{array}$ & Protein annotation & $\begin{array}{l}\text { MY } \log _{2} \\
\text { (FL/CL) }\end{array}$ & $\begin{array}{l}\mathrm{MM} \log _{2} \\
\text { (FL/CL) }\end{array}$ & $\begin{array}{l}\mathrm{EY} \log _{2} \\
(\mathrm{FL} / \mathrm{CL})\end{array}$ & $\begin{array}{l}\mathrm{EM} \log _{2} \\
(\mathrm{FL} / \mathrm{CL})\end{array}$ & Peptides \\
\hline O65581 & AT4G26530 & FBA5 & fructose-bisphosphate aldolase 5 , cytosolic & 0.62 & 0.48 & 0.62 & 0.41 & 19 \\
\hline O81439 & AT4G04020 & $\begin{array}{l}\text { FBN1A; } \\
\text { PAP1 }\end{array}$ & fibrillin family protein; plastid-lipid-associated protein 1 & 0.55 & 0.29 & 0.67 & 0.39 & 16 \\
\hline O82392 & AT2G29630 & $\mathrm{THIC}$ & $\begin{array}{l}\text { hydroxymethylpyrimidine phosphate synthase; thiamine } \\
\text { biosynthesis protein C }\end{array}$ & 0.36 & 0.29 & 0.26 & 0.21 & 18 \\
\hline $\begin{array}{l}\text { Q94B78; } \\
\text { B3H5Y8 }\end{array}$ & AT4G33010 & GLDP1 & glycine decarboxylase P protein 1 & 0.32 & 0.30 & 0.35 & 0.19 & 43 \\
\hline $\begin{array}{l}\text { F4K410; } \\
\text { F4K409 }\end{array}$ & AT5G13650 & SVR3 & $\begin{array}{l}\text { putative TypA-like translation elongation GTPase; } \\
\text { suppressor of variegation } 3\end{array}$ & 0.29 & 0.42 & 0.32 & 0.24 & 20 \\
\hline $\begin{array}{l}\text { Q04836; } \\
\text { Q04836-2 }\end{array}$ & AT4G24770 & RBP31 & 31 kDa RNA-binding protein, chloroplastic & 0.22 & 0.25 & 0.25 & 0.25 & 8 \\
\hline Q8L7C9 & AT1G78370 & GSTU20 & glutathione S-transferase U20 & -0.27 & -0.42 & -0.63 & -0.51 & 11 \\
\hline P42761 & AT2G30870 & $\begin{array}{l}\text { GSTF10; } \\
\text { ERD13 }\end{array}$ & $\begin{array}{l}\text { glutathione S-transferase F10; early response to } \\
\text { dehydration } 13\end{array}$ & -0.35 & -0.36 & -0.41 & -0.37 & 9 \\
\hline
\end{tabular}

(Figure 2D). Notably, the correlation between the individual replicates of the end-of-day samples (EY and EM) was stronger than the correlation between those of the morning samples (MY and $\mathrm{MM}$ ), indicating clearer and more consistent changes happening in leaf proteome at the end of day under the FL condition.

We next determined proteins with significantly altered abundance under FL using LIMMA-moderated t-test (Ritchie et al., 2015; Phipson et al., 2016) with a FDR-adjusted p-value of $\leq 0.05$ as significance threshold (Figure 3). Even though the numbers of reliably quantified proteins and the FL/CL ratio
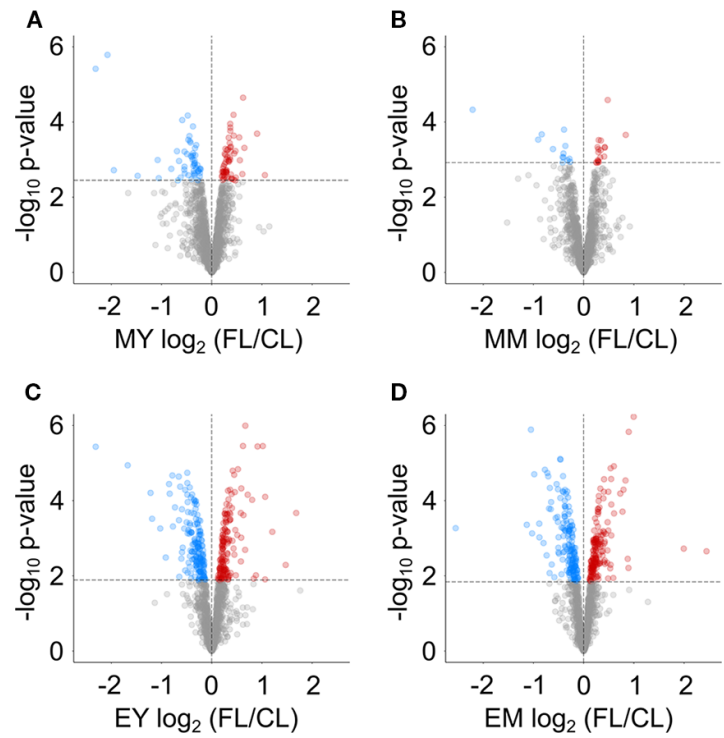

FIGURE 3 | Volcano plots indicating proteins with significant changes in abundance in FL compared to CL at (A) MY, (B) MM, (C) EY and (D) EM. Dashed lines indicate the chosen significance thresholds with a BenjaminiHochberg corrected FDR $<0.05$. Blue circles indicate depleted, red circles accumulating proteins. distributions were comparable in all four samples (Figure 2B), only 112 and 31 proteins passed this threshold in MY and MM, respectively, whereas 341 and 321 proteins showed significant changes in EY and EM (Figure 3). These results provide a further support to greater proteome adjustments occurring in leaves after $11 \mathrm{~h}$ FL exposure (end of day) than after $1 \mathrm{~h}$ FL exposure (morning) on day 3.

\section{A Core Set of FL-Responsive Proteins in Leaves}

Only eight proteins showed significant changes in abundance in all four samples under FL (Figure 4A, Table 1). Six of these underwent a significant increase under FL, namely, four chloroplast-located proteins fibrillin 1A (FBN1A), thiamine biosynthesis protein $\mathrm{C}$ (THIC), $31 \mathrm{kDa}$ RNA-binding protein (RBP31), and a putative translation elongation factor (suppressor of variegation 3, SVR3), as well as cytosolic fructose-bisphosphate aldolase 5 (FBA5) involved in glycolysis and gluconeogenesis and mitochondrial glycine decarboxylase $\mathrm{P}$ protein 1 (GLDP1) catalyzing photorespiratory $\mathrm{CO}_{2}$ release. Two cytosolic glutathione S-transferases (GSTF10 and GSTU20) were the only proteins that declined in all samples under FL. Another 41 proteins showed significant increase or decrease in three out of four samples (Figure 4A). Of these, 31 and six did not pass the significance threshold in MM and MY, respectively, whereas only one did not pass in each of EY and EM. As was seen in Figure 2D, EY and EM had the largest overlap of the significantly changing proteins while much fewer proteins were common in young and mature leaves in the morning or in the same leaves between the two time points (Figure 4A, B). Still, a consistent trend of increase or decrease was observed for almost all 41 proteins in MY, MM, EY, and EM (Table 2), suggesting that these proteins responded to FL in a more or less similar manner, independently of time of day and leaf development stage. We therefore consider these 49 proteins in Tables $\mathbf{1}$ and $\mathbf{2}$ as a core set of FL-responsive proteins in leaves during long-term acclimation to FL.

About a half of these proteins (26) were found to be increased and the other half (23) decreased after 3-d FL exposure. The 
TABLE 2 | Proteins with significant responses to FL in three of the four samples (MY, MM, EY, and EM). Significant changes are indicated by bold numbers.

\begin{tabular}{|c|c|c|c|c|c|c|c|c|}
\hline $\begin{array}{l}\text { Majority protein } \\
\text { IDs }\end{array}$ & AGI locus & $\begin{array}{l}\text { Gene } P \\
\text { names }\end{array}$ & Protein names and descriptions & $\begin{array}{l}\text { MY } \log _{2} \\
\text { (FL/CL) }\end{array}$ & $\begin{array}{l}\mathrm{MM} \log _{2} \\
\text { (FL/CL) }\end{array}$ & $\begin{array}{l}E Y \log _{2} \\
(\mathrm{FL} / \mathrm{CL})\end{array}$ & $\begin{array}{l}\mathrm{EM} \log _{2} \\
(\mathrm{FL} / \mathrm{CL})\end{array}$ & Peptides \\
\hline Q94AG1 & AT3G07470 & & putative transmembrane protein (DUF538) & 1.06 & 0.19 & 1.06 & 0.88 & 5 \\
\hline Q00218; F4JIZ3 & AT4G33510 & DHS2 & $\begin{array}{l}\text { 3-deoxy-D-arabino-heptulosonate } 7 \text { - } \\
\text { phosphate synthase } 2\end{array}$ & 0.27 & 0.38 & 0.58 & 0.54 & 14 \\
\hline Q94A68 & AT1G06690 & & $\begin{array}{l}\text { NAD(P)-linked oxidoreductase superfamily } \\
\text { protein, chloroplastic }\end{array}$ & 0.33 & 0.31 & 0.40 & 0.40 & 10 \\
\hline Q2V2S7 & AT4G37925 & NDHM & NDH-like complex subunit M & 0.34 & 0.42 & 0.37 & 0.33 & 9 \\
\hline $\begin{array}{l}\text { Q8L7S8; Q8L7S8-2; } \\
\text { F4K180 }\end{array}$ & AT5G26742 & $\begin{array}{l}\text { RH3; } \\
\text { EMB1138 }\end{array}$ & $\begin{array}{l}\text { DEAD box ATP-dependent RNA helicase 3, } \\
\text { chloroplastic; embryo defective } 1138\end{array}$ & 0.23 & 0.42 & 0.27 & 0.33 & 26 \\
\hline O49629 & AT4G22240 & $\begin{array}{l}\text { FBN1B; } \\
\text { PAP2 }\end{array}$ & $\begin{array}{l}\text { fibrillin family protein; plastid-lipid-associated } \\
\text { protein } 2 \text {, chloroplastic }\end{array}$ & 0.37 & 0.10 & 0.59 & 0.32 & 9 \\
\hline Q9FI56 & AT5G50920 & CLPC1 & $\begin{array}{l}\text { ATP-dependent Clp protease ATP-binding } \\
\text { subunit C homologue } 1\end{array}$ & 0.24 & 0.28 & 0.14 & 0.28 & 43 \\
\hline P56772 & ATCG00670 & clpP & $\begin{array}{l}\text { ATP-dependent Clp protease plastid- } \\
\text { encoded proteolytic subunit }\end{array}$ & 0.10 & 0.33 & 0.19 & 0.27 & 4 \\
\hline $\begin{array}{l}\text { F4KDZ4; Q9ZP05; } \\
\text { A8MRP1; B3H560 }\end{array}$ & AT5G09660 & $\mathrm{PMDH} 2$ & malate dehydrogenase 2 , peroxisomal & 0.03 & 0.27 & 0.33 & 0.25 & 17 \\
\hline Q56YA5 & AT2G13360 & SGAT & serine-glyoxylate aminotransferase & 0.27 & 0.38 & 0.36 & 0.24 & 22 \\
\hline Q9LK47 & AT3G23700 & SRRP1 & S1 RNA-binding ribosomal protein 1 & 0.32 & 0.28 & 0.31 & 0.23 & 11 \\
\hline $\begin{array}{l}\text { Q9SJU4; F4IGL5; } \\
\text { F4IGL7 }\end{array}$ & AT2G21330 & FBA1 & $\begin{array}{l}\text { fructose-bisphosphate aldolase } 1 \text {, } \\
\text { chloroplastic }\end{array}$ & 0.29 & 0.21 & 0.35 & 0.23 & 19 \\
\hline P17745 & AT4G20360 & $\begin{array}{l}\text { RABE1B; } \\
\text { SVR11 }\end{array}$ & $\begin{array}{l}\text { translation elongation factor Tu, } \\
\text { chloroplastic; suppressor of variagation } 11\end{array}$ & 0.24 & 0.21 & 0.21 & 0.22 & 22 \\
\hline Q9SHG8 & AT1G17100 & HBP1 & heme-binding protein 1 & 0.36 & 0.17 & 0.32 & 0.22 & 8 \\
\hline P25819; F4JM86 & AT4G35090 & СAT2 & catalase 2 & 0.29 & 0.28 & 0.31 & 0.21 & 21 \\
\hline Q9MA79 & AT1G43670 & CFBP & fructose-1,6-bisphosphatase, cytosolic & 0.37 & 0.22 & 0.29 & 0.20 & 15 \\
\hline P54150 & AT4G25130 & MSR4 & $\begin{array}{l}\text { peptide methionine sulfoxide reductase A4, } \\
\text { chloroplastic }\end{array}$ & 0.25 & 0.22 & 0.27 & 0.19 & 5 \\
\hline O65396 & AT1G11860 & GDCST & glycine decarboxylase $T$ protein & 0.27 & 0.09 & 0.23 & 0.18 & 22 \\
\hline Q9SA52 & AT1G09340 & CSP41B & $\begin{array}{l}\text { stem-loop RNA binding protein of } 41 \mathrm{kDa} \mathrm{B} \text {, } \\
\text { chloroplastic }\end{array}$ & 0.21 & 0.12 & 0.24 & 0.17 & 22 \\
\hline 080448 & AT2G38230 & PDX1.1 & pyridoxal 5'-phosphate synthase subunit 1.1 & 0.37 & 0.34 & 0.31 & 0.16 & 16 \\
\hline Q6NPR7 & AT1G29470 & & $\begin{array}{l}\text { S-adenosyl-L-methionine-dependent } \\
\text { methyltransferases superfamily protein }\end{array}$ & -0.37 & & -0.20 & -0.18 & 8 \\
\hline Q39255 & AT1G75950 & SKP1A & SKP1 homologue $1 \mathrm{~A}$ & -0.22 & & -0.23 & -0.18 & 3 \\
\hline O04487 & AT1G09640 & & $\begin{array}{l}\text { translation elongation factor EF1B, gamma } \\
\text { chain } 1\end{array}$ & -0.31 & -0.22 & -0.26 & -0.20 & 16 \\
\hline O04151;F41529 & AT1G56340 & $\begin{array}{l}\text { CRT1; } \\
\text { CRT1A }\end{array}$ & calreticulin 1 ; calreticulin $1 \mathrm{~A}$ & -0.37 & -0.20 & -0.36 & -0.22 & 12 \\
\hline P56780 & ATCG00710 & $\mathrm{psbH}$ & $\begin{array}{l}10 \text { kDa PSIl reaction center phosphoprotein } \\
\mathrm{H}\end{array}$ & -1.08 & -0.40 & -0.48 & -0.25 & 1 \\
\hline Q9LIA8 & AT3G29360 & UGD2 & UDP-glucose 6-dehydrogenase 2 & -0.34 & -0.29 & -0.35 & -0.26 & 15 \\
\hline Q9SIN5 & AT2G42530 & COR15B & cold-regulated 15B, chloroplastic & -0.62 & -0.30 & -0.26 & -0.27 & 10 \\
\hline O80852;080852-2 & AT2G30860 & GSTF9 & glutathione S-transferase F9 & -0.36 & -0.28 & -0.40 & -0.28 & 8 \\
\hline O82514;F4KAP2 & AT5G63400 & ADK1 & adenylate kinase 1 & -0.81 & -0.24 & -0.31 & -0.29 & 10 \\
\hline Q96252 & AT5G47030 & & $\begin{array}{l}\text { ATP synthase F1 subunit delta', } \\
\text { mitochondrial }\end{array}$ & -0.47 & -0.40 & & -0.29 & 3 \\
\hline $\begin{array}{l}\text { P42794; P42794-2; } \\
\text { P42795 }\end{array}$ & $\begin{array}{l}\text { AT2G42740; AT3G58700; } \\
\text { AT4G18730; AT5G45775 }\end{array}$ & $\begin{array}{l}\text { RPL16A; } \\
\text { RPL16B }\end{array}$ & 60S ribosomal protein L16A; L16B & -0.10 & -0.32 & -0.35 & -0.30 & 8 \\
\hline $\begin{array}{l}\text { A8MSC5; O22263; } \\
\text { F4IL52; F4IL53 }\end{array}$ & AT2G47470 & PDl11 & protein disulfide isomerase 11 & -0.21 & -0.39 & -0.33 & -0.33 & 11 \\
\hline Q9LUT2 & AT3G17390 & MAT4 & methionine adenosyltransferase 4 & -0.25 & -0.32 & -0.35 & -0.38 & 20 \\
\hline $\begin{array}{l}\text { Q42547; B9DG18; } \\
\text { F4HUL6; Q2V4M4 }\end{array}$ & AT1G20620 & CAT3 & catalase 3 & -0.59 & -0.39 & -0.59 & -0.38 & 20 \\
\hline P21218 & AT4G27440 & PORB & $\begin{array}{l}\text { NADPH:protochlorophyllide oxidoreductase } \\
\text { B }\end{array}$ & -0.33 & -0.24 & -0.28 & -0.42 & 20 \\
\hline Q9SXS7; F4K5T1 & AT5G28020 & CYSD2 & cysteine synthase D2 & -0.38 & -0.35 & -0.48 & -0.47 & 5 \\
\hline F4HST2; P42759 & AT1G20450 & $\begin{array}{l}\text { ERD10; } \\
\text { LTI29 }\end{array}$ & $\begin{array}{l}\text { early response to dehydration 10; low } \\
\text { temperature-induced } 29\end{array}$ & -0.69 & -0.33 & -0.46 & -0.52 & 8 \\
\hline Q9ZPZ4 & AT1G09310 & & protein of unknown function (DUF538) & -0.48 & -0.46 & -0.53 & -0.67 & 10 \\
\hline Q945Q5 & AT2G30695 & & bacterial trigger factor & 0.10 & -0.84 & -0.85 & -0.71 & 6 \\
\hline P31168 & AT1G20440 & COR47 & dehydrin; cold-regulated 47 & -0.54 & -0.77 & -0.77 & -0.72 & 8 \\
\hline Q8RWG5 & AT2G16630 & FOCL1 & $\begin{array}{l}\text { fused outer cuticular ledge } 1 \text {; pollen Ole e } 1 \\
\text { allergen and extensin family protein }\end{array}$ & -2.08 & -2.21 & -2.31 & & 1 \\
\hline
\end{tabular}




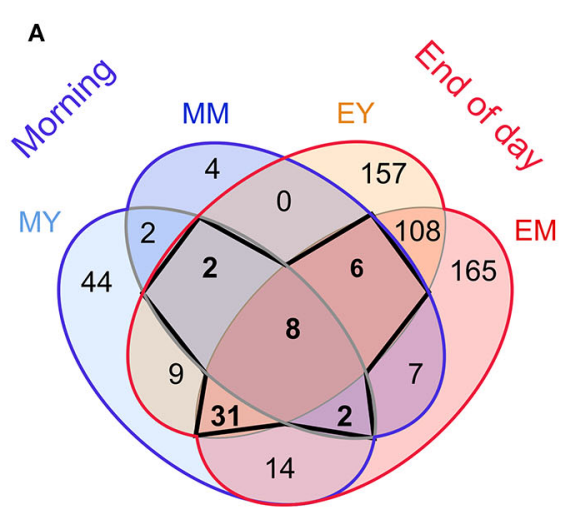

B Morning
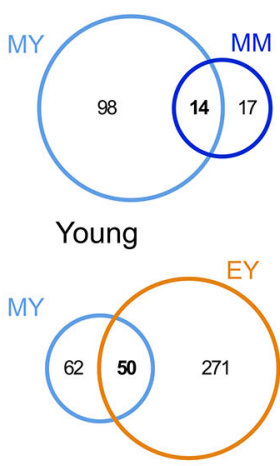

Young
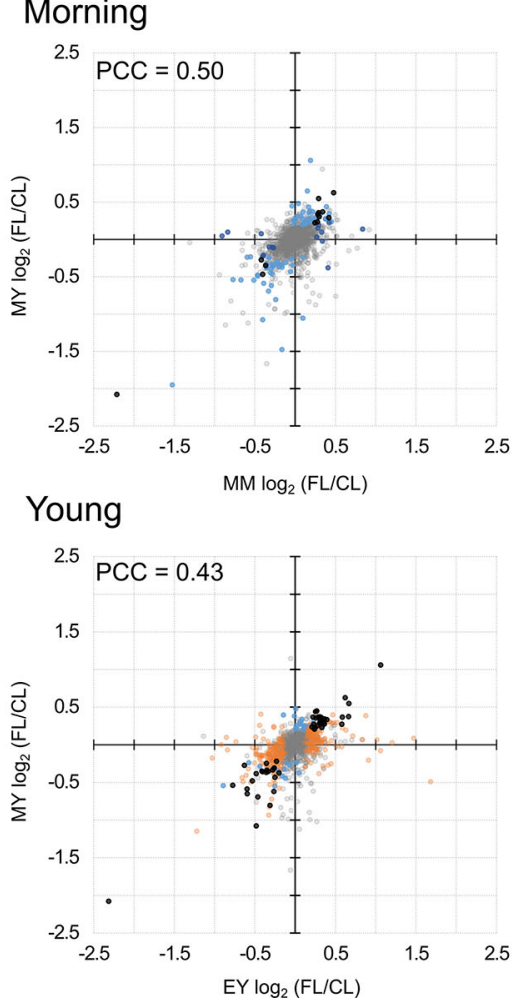

Young

End of day

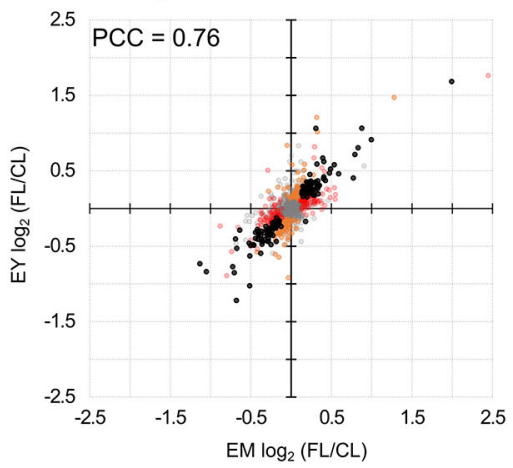

Mature

End of day
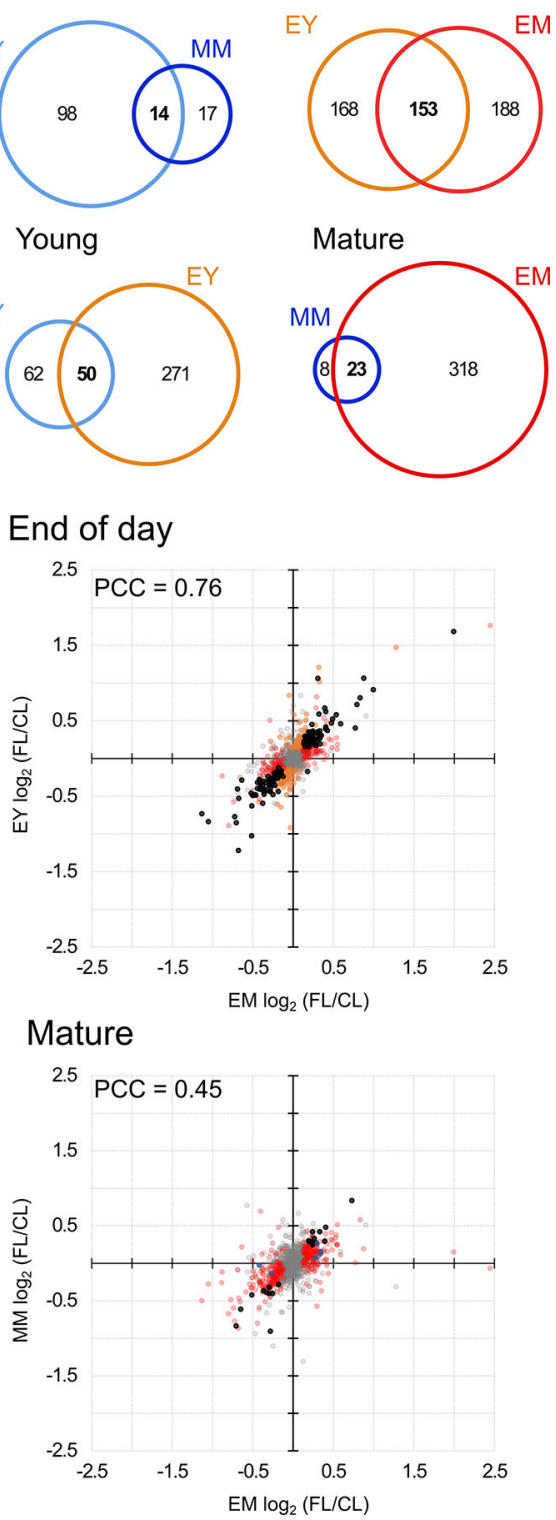

FIGURE 4 | Comparison of proteins with significant FL-induced changes in abundance in each sample. (A) Overlap of significant changes in abundance in morning and at the end of day in both young and mature leaves. Bold numbers indicate the 49 proteins significantly changed in four or three samples. (B) Pairwise overlap of significant changes in protein abundance in the morning, at the end of day, in young leaves and in mature leaved. (C) Correlation of protein abundance ratio FL/CL between different samples. Colors indicate the sample in which the protein ratio was found to be significantly altered light blue, MY; dark blue, MM; orange, EY; red, EM. Black dots indicates significant change in both samples (overlap of Venn diagrams) and grey indicates no significant change. PCC, Pearson correlation coefficient.

analysis of associated GO terms indicated an enrichment of chloroplast proteins and enzymes involved in central carbon metabolism among the significantly increasing proteins, including those in carbon fixation, photorespiration, pentose phosphate pathway, glycolysis, and gluconeogenesis (Supplementary Table 2). In contrast, many proteins, which were less abundant in FL than in CL, were not localized in chloroplasts and no particular metabolic pathway was enriched (Supplementary Table 3).

Of the core set of 49 FL-responsive proteins, a putative transmembrane protein (AT3G07470) underwent the strongest increase of $+85 \sim 110 \%$ in MY, EY, and EM (Table 2). In addition, young and mature leaves showed $45 \% \sim 60 \%$ and $25 \% \sim 40 \%$ increase, respectively, in the aforementioned cytosolic FBA5 
and FBN1A in plastoglobuli at both time points (Table 1). One of the three isoforms of 3-deoxy-D-arabino-heptulosonate 7phosphate synthase (DHS2), which catalyzes the first committed step of aromatic amino acid biosynthesis in the Shikimate pathway, also exhibited an increasing trend of $+45 \% \sim 50 \%$ (end of day) or $+20 \% \sim 30 \%$ (morning) (Table 2). On the other hand, a protein involved in guard cell outer cuticular ledge formation (FOCL1), which affects the size of guard cells and the aperture of stomatal pore (Hunt et al., 2017), was diminished by 75\% 80\% in both leaves at both time points, although the change was not statistically significant in EM. A marked decrease was also observed for a bacterial trigger factor-like protein $(30 \% \sim 40 \%)$ and cold- and dehydration-regulated protein 47 (COR47) (40\% $\sim 45 \%$ ) with an exception in MM and MY, respectively, in which these proteins showed a non-significant decrease or increase (Table 2). However, compared to the other three, MY had more pronounced decrease of plastid-encoded $10 \mathrm{kDa}$ PSII reaction center protein $\mathrm{psbH}(-50 \%)$ and an adenylate kinase-like protein ADK1 (-40\%) which monitors and interconverts ATP, ADP, and AMP in the cell. Interestingly, two catalase isoforms CAT2 and CAT3, which detoxify $\mathrm{H}_{2} \mathrm{O}_{2}$ in peroxisome, were both responding to FL but in the opposite directions, with CAT2 being 15\%-25\% more and CAT3 25\%-35\% less abundant under FL compared to CL.

\section{Time-of-Day-Specific Responses to FL}

The Venn diagram (Figure 4A) pointed to a large number of additional proteins (430) which underwent significant changes in abundance only at the end of day, with 108 affected both in EY and EM. In contrast, only 50 proteins were significantly increased or decreased exclusively in the morning and no more than two proteins were shared by MY and MM. In order to quantify the similarities and differences among the four samples, we plotted changes in the protein abundance (FL/CL ratios) in the pairwise comparisons (Figure 4B). When data of all proteins quantified in at least three of the five biological replicates were included, the highest Pearson correlation coefficient (PCC) was found for the comparison of young and mature leaves at the end of day (Figure 4C). The correlation coefficient was much lower for the other three comparisons, consistent with the correlations found between the individual FL/CL replicates (Figure 2D). Together, the results of these analyses underline a higher similarity in FL-induced proteomic responses of young and mature leaves at the end of day than in the morning, and also distinct responses of the same leaves between morning and the end of day.

Proteins, which were significantly increased in both EY and EM but not in the morning, are enriched in chloroplast proteins and enzymes of central carbon metabolism (Supplementary Table 4), in much the same way as for the core set of significantly increasing proteins in FL (Supplementary Table 2). Thus, it seems that accumulation of certain chloroplastic and carbon metabolic proteins was constitutively enhanced in leaves under FL while other proteins increased more strongly towards the end of day. In addition, the proteins undergoing end-of-dayspecific increase are also overrepresented by the components of oxidation-reduction, RNA binding and response to chemical or cold (Supplementary Table 4). Similarly, the GO terms, which are enriched in the proteins with end-of-day-specific decrease (Supplementary Table 5), are partly identical with those of the core set of significantly decreasing proteins (Supplementary Table 3), such as cytoplasm and cytosol or response to cadmium and inorganic substance. However, proteins with end-of-day-specific decrease were additionally associated with unique GO terms, e.g., sulfur-containing proteogenic amino acid metabolism, protein processing in endoplasmic reticulum, and ribosomes along with response to abiotic stimuli (temperature, heat) (Supplementary Table 5).

\section{Correlation Between FL-Induced Changes in Leaf Proteome and Transcriptome}

Our recent RNA sequencing study identified 1,041, 266, 819, and 2,402 differentially expressed genes ( $>30 \%$ changes in transcript abundance) in MY, MM, EY, and EM samples taken from the plants under the same FL and CL conditions (Schneider et al., 2019). Part of these gene expression responses were in line with the phenotypic changes observed at the level of growth and photosynthesis or pigments and other leaf metabolites. In order to make a comparison with the protein responses, we checked the FL-induced changes in protein abundance, focusing on the pathways reported in the transcriptome study (Schneider et al., 2019), namely, photosynthesis (light reactions, the CalvinBenson cycle and their regulation), photorespiration and metabolism of pigments, prenylquinones and vitamin B6. Supplementary Table 6 lists abundance ratios for selected proteins quantified in at least three replicates of all four samples, even if they did not meet the chosen significance thresholds. Generally, distribution of increasing or decreasing proteins is highly heterogenous among the pathways, suggesting both pathway- and component-specific regulation of protein abundance during long-term FL acclimation.

For example, the components of PSII and PSI, especially some subunits of oxygen evolving complex in the morning and PSI reaction center in mature leaves, tended to decrease under FL (Supplementary Table 6). In contrast, the components of intersystem and cyclic electron transport were mostly increased, as were those of thylakoid ATP synthase. Many thioredoxins (TRXs) and redox regulatory enzymes of chloroplasts were also more likely to increase than decrease in FL. The Calvin-Benson cycle and photorespiratory enzymes seemed to undergo small but concerted increase, which more frequently passed our significance criteria in young leaves than in mature leaves. The exceptions to this increase were the small subunit of Rubisco (RBCS) and catalase 3 (CAT3), which showed minor or strong decrease, respectively. Apart from the suppression of protochlorophyllide reductase B (PORB) accumulation, the abundance of chlorophyll biosynthetic enzymes changed rather weakly while several enzymes in the isoprenoid and tocopherol biosynthetic pathways increased. Similarly, the protein levels were also increased for two isoforms of pyridoxal 5'-phosphate synthase subunit 1 (PDX1). 
The changes in protein abundance observed in these pathways correspond largely but not entirely to the gene expression changes described in our previous study (Schneider et al., 2019). In fact, we found a universal shift in the relative proportions of significantly increasing and decreasing proteins and genes (Figure 5A). Proteins exhibiting significantly increased and reduced abundance under FL were in nearly equal proportions (approximately 50\%) in each of the four samples, whereas upregulation was clearly the predominant response at the level of gene expression. Since the numbers of significantly increasing or decreasing proteins and genes detected by the proteome and transcriptome analyses differed substantially, the intersections between the global changes of proteome and transcriptome are not large (Supplementary Figure 2). In total, 145 unique proteins/genes were significantly and concurrently changing in abundance in the corresponding leaves at the same time points.

Counting also the responses of the same proteins/genes in multiple samples, we obtained 169 individual relations of protein and transcript abundance for pairwise comparison, mostly from EM (Figure 5B). The majority of the proteins/genes (138) clustered in the upper right corner of the plot, representing parallel increase in both protein and transcript under FL (Supplementary Table 7). This included many components associated with GO terms related to chloroplast transcription and translation, photosynthesis and photorespiration, plastid organization, and oxidation-reduction process (Supplementary Table 8). For most of them, the measured increase was greater at the mRNA level than at the protein level. Only seven had larger FL/CL ratios for protein abundance, of which three are in chloroplasts: ferredoxin:thioredoxin reductase catalytic subunit (FTRB), atypical Cys/His-rich thioredoxin 2 (ACHAT2), and redox-regulated glucose-6-phosphate dehydrogenase 1 (G6PD1). The other four are peroxisomal acyl-activating enzyme 7 (AAE7) having short-chain acetyl-CoA synthetase activity, cytosolic carotenoid cleavage dioxygenase 1 (CCD1), an ABC transporter family protein $(\mathrm{ABCB} 28)$ and an unknown transmembrane protein (AT2G05310; AT4G13500). The accumulation of these seven proteins was enhanced in EM while AAE7 was also increased in EY (Supplementary Table 7).

In contrast, only 16 proteins/transcripts clustered in the lower left corner (Figure 5B) indicating concomitant downregulation in FL (Supplementary Table 9). This included proteins linked to peroxisomal and cytosolic ROS processing (CAT3; dehydroascorbate reductase 1, DHAR1; annexin D1), protein folding in endoplasmic reticulum (protein disulfide isomeraselike proteins PDIL1-1 and PDIL2-1; HSP70-family proteins BIP1 and HSP70-17; calreticulin 1, CRT1), and chlorophyll biosynthesis (PORB). In most cases, the decrease was larger at the mRNA level (Supplementary Table 9).

Intriguingly, nine data points (all from EM) appeared in the upper left corner, showing a decrease in protein abundance despite increased transcript abundance (Figure 5B). Eight of these proteins are (or are predicted to be) localized in chloroplasts (Table 3): Rubisco small subunit 1B (RBCS1B) and glyceraldehyde-3 phosphate dehydrogenase A1 (GAPA1)

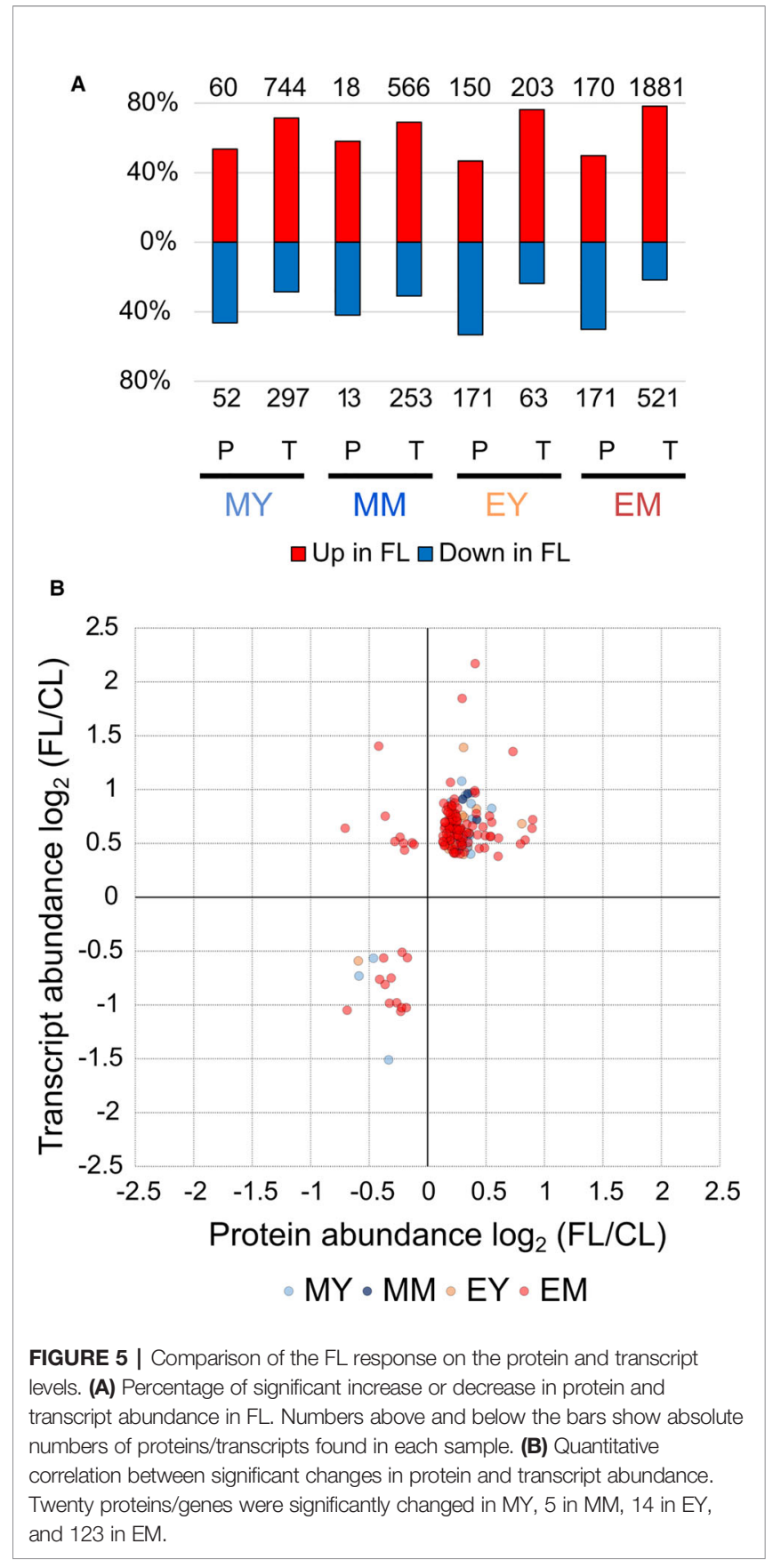

in the Calvin-Benson cycle, MAR-binding filament-like protein 1 (MFP1) associated with nucleoids and thylakoids, 50S ribosomal protein L13 family protein (EMB1473), threonyl-tRNA synthetase (EMB2761), plasma membrane fusion protein (AT5G42765), bacterial trigger factor (AT2G30695), and saccharopine dehydrogenase (AT1G50450). The only nonchloroplastic protein in this group, sinapoylglucose:malate $\mathrm{O}$ sinapoyltransferase (SNG1 or SCPL8), is an enzyme which synthesizes a UV screening compound sinapoyl malate in leaves. Diagonal to these, no single protein/gene was found in the lower right corner combining protein increase with transcript 
TABLE 3 | Proteins and genes with contrasting FL responses of protein and transcript abundance in mature leaves at the end of day. Localization annotation is the consensus listed in the SUBA database. Significant changes in abundance are indicated by bold letters.

\begin{tabular}{|c|c|c|c|c|c|c|}
\hline $\begin{array}{l}\text { Majority } \\
\text { protein IDs }\end{array}$ & AGI locus & Gene names & Protein annotation & Localization & $\begin{array}{c}\text { protein } \\
\text { log2 } \\
\text { (FL/CL) }\end{array}$ & $\begin{array}{c}\text { transcript } \\
\text { log2 } \\
\text { (FL/CL) }\end{array}$ \\
\hline P10796 & AT5G38430 & RBCS1B & Rubisco small subunit 1B & plastid & -0.24 & 0.56 \\
\hline P25856 & AT3G26650 & GAPA1 & $\begin{array}{l}\text { glyceraldehyde-3-phosphate dehydrogenase A subunit 1, } \\
\text { chloroplastic }\end{array}$ & plastid & -0.12 & 0.49 \\
\hline Q9LW85 & AT3G16000 & MFP1 & MAR-binding filament-like protein 1 & plastid & -0.20 & 0.44 \\
\hline Q9SYL9 & AT1G78630 & EMB1473 & 50 S ribosomal protein L13 family protein, chloroplastic & plastid & -0.21 & 0.50 \\
\hline F4IFC5 & AT2G04842 & EMB2761 & threonyl-tRNA synthetase, chloroplastic/mitochondrial & $\begin{array}{l}\text { plastid, } \\
\text { mitochondria }\end{array}$ & -0.13 & 0.51 \\
\hline F4K329 & AT5G42765 & & plasma membrane fusion protein & plastid & -0.28 & 0.52 \\
\hline Q945Q5 & AT2G30695 & & bacterial trigger factor & plastid & -0.71 & 0.64 \\
\hline Q94BZ0 & AT1G50450 & & saccharopine dehydrogenase & plastid & -0.36 & 0.75 \\
\hline $\begin{array}{l}\text { A8MR78; } \\
\text { Q8RUW5; } \\
\text { Q8RUW5-2; } \\
\text { Q3EBW0; } \\
\text { F4IKK4; } \\
\text { A8MQW0 }\end{array}$ & AT2G22990 & $\begin{array}{l}\text { SNG1; } \\
\text { SCPL8 }\end{array}$ & sinapoylglucose:malate O-sinapoyltransferase & extracellular & -0.42 & 1.40 \\
\hline
\end{tabular}

decrease (Figure 5B). Together, the results in Figure 5B suggest that FL-induced changes in transcript abundance are mostly reflected in the changes in protein levels, although some proteins may accumulate to lower levels despite increased transcription.

\section{DISCUSSION}

Concordant with the recent transcriptome study (Schneider et al., 2019), our quantitative proteome analysis revealed distinct acclimatory changes in protein composition and abundance of MY, MM, EY, and EM after 3-d in the FL condition (Figure 4), underpinning developmentally and temporally heterogeneous adjustments of leaf proteome within a small rosette of Arabidopsis during acclimation. At the protein level, the FL responses of young and mature leaves were greater and also more similar at the end of day than in the morning (Figures 3 and 4B), whereas their gene expression responses were overlapping more strongly in the morning (Schneider et al., 2019). While we found partly comparable changes in transcript and protein abundance, there were also differences in their responses, such as the relative importance of downregulation being greater at the protein level than the transcript level (Figure $\mathbf{5 A}$ ) and the decline in protein abundance despite upregulation of gene expression seen for some proteins (Figure 5B). Obviously, FL acclimation entails post-transcriptional control involving regulation of translation and protein turnover as proposed for HL acclimation (Oelze et al., 2014; Li et al., 2018). Below, we discuss key findings of our study and their implications for mechanisms of long-term FL acclimation.

\section{Acclimation to FL Entails Both Constitutive and Dynamic Adjustments of Proteome}

In agreement with the transcript data (Schneider et al., 2019), we found both consistent and distinct proteome alterations in the four samples during acclimation to FL (Figure 4). Similar to the transcriptional changes and consistent with the lack of visible stress symptoms (Schneider et al., 2019), changes in protein abundance were very moderate, with few proteins exhibiting more than $50 \%$ changes in any sample. The core set of 49 proteins (Tables 1 and 2) showing significant changes in abundance in three or four of the four samples (MY, MM, EY, and EM) suggest constitutive responses to FL shared by young and mature leaves in the morning and at the end of day. These constitutive responses included enhanced accumulation of proteins involved in formation of plastoglobuli and stress response (FBN1A, FBN1B), CEF around PSI (NDHM), photorespiration (GLDP1, SGAT, CAT2, GDCST), and glycolytic enzymes (FBA5, CFBP). This pattern is consistent with the previously observed alterations in leaf transcriptome and phenotype which were associated with reduced linear electron transport, increased photoprotection, decreased sugar and starch accumulation, and growth reduction (Alter et al., 2012; Schneider et al., 2019). In contrast, several glutathione S-transferases (GSTU20, GSTF9, GSTF10), cold-regulated proteins (COR15B, COR47) and proteins involved in translation (bacterial trigger factor, elongation factor EF1B, ribosomal protein RPL16) were consistently depleted under the FL condition (Tables 1 and 2).

In addition to these constitutive changes, only a relatively small number of proteins exhibited significant changes in abundance under FL in the morning (Figure 4). In contrast, many proteins (430) showed significant changes in abundance in young and/or mature leaves at the end of day under FL (Figures 3 and 4), including proteins of the same functional categories as the core set, but also those associated with other stress-related GO categories such as "protein processing in endoplasmic reticulum" and "response to abiotic stimuli (temperature, heat)". Although similar patterns were also recognized in the corresponding leaves in the morning, the changes became more significant at the end of day, suggesting additional stimuli or signals generated in the course of the day under FL to strengthen these responses. 
Especially striking is the significant accumulation of photorespiratory enzymes in EY and decrease in PSI complex subunits in EM (Supplementary Table 6). Upon sudden increase in light intensity, the components of light reactions respond more rapidly than the Calvin-Benson cycle, which in turn is quicker than stomatal guard cell movement. Consequently, $\mathrm{CO}_{2}$ concentration transiently drops inside the leaf (Vialet-Chabrand et al., 2017) and hence also in chloroplast stroma during light intensity fluctuation. This was shown to boost photorespiration even in leaves of tobacco plants grown under full sunlight (Huang et al., 2015). The concerted upregulation of many photorespiratory proteins/genes found in this study and our previous RNA sequencing analysis under the FL condition (Schneider et al., 2019) is in line with limitation of photosynthetic carbon fixation by temporally low $\mathrm{CO}_{2}$ availability in $\mathrm{C} 3$ plants. Indeed, a recent study in cassava reported a major impact of stomatal conductance to limit dynamic photosynthesis in FL (De Souza et al., 2020). Signals that trigger the upregulation of photorespiratory genes and proteins under FL are not yet known.

It has been suggested that PSI is susceptible to photoinhibition and oxidative damage when excess electrons arrive from PSII (Tikkanen et al., 2012). Thus, PSI needs to be protected by downregulating PSII through NPQ and alleviating acceptor side limitation by, for example, CEF and photorespiration under FL conditions. In accordance, the Arabidopsis leaf transcriptomes showed concomitant upregulation of many genes related to these processes (Schneider et al., 2019) and our proteome analysis confirmed an increase in protein abundance for some of them (Table 2 and Supplementary Table 6). In particular, mature leaves exhibited concurrent upregulation of NDH-like complex genes at the end of day, suggesting a role of $\mathrm{NDH}$-dependent $\mathrm{CEF}$ in these leaves under our FL condition (Schneider et al., 2019). The accumulation of the NDH-like complex and its chloroplastencoded subunits (ndhA and ndhF) has been shown to increase in barley leaves under photooxidative conditions or following $\mathrm{H}_{2} \mathrm{O}_{2}$ treatment (Martín et al., 1996; Casano et al., 2001).

Leaves exposed to FL had lower protein levels of PS I subunits (Supplementary Table 6), which supports the notion of PSI photoinhibition and degradation. Far-red (FR) light protects PSI against photoinhibition under FL (Kono et al., 2017). The protective effects of FR illumination were substantially reduced in mutants lacking NDH-dependent CEF, suggesting the contribution of this alternative electron transport pathway in natural FR-rich FL environments (Kono et al., 2017). Our growth light conditions had very high red-to-FR ratio (4 to 5; Supplementary Figure 1) compared to natural sunlight ( 1.2) or canopy shade (0.1 to 0.2 ) (Franklin, 2008), which could have exacerbated PSI photoinhibition in our experiments.

\section{Acclimatory Adjustment of Protein Abundance Involves Pathway- and Protein-Specific Changes in Synthesis and Degradation}

After 3-d exposure to FL, most changes in protein abundance were rather small and challenging to detect even with the precision of stable isotope-based quantification such as the chemical labeling method employed here (Altelaar et al., 2013). To identify broader trends, we therefore inspected changes in protein abundance in selected protein complexes and pathways of interest, irrespective of whether they passed the chosen significance criteria or not (Supplementary Table 6).

Among the protein complexes involved in photosynthetic electron transport, the abundance of PSI subunits tended to decrease in FL as discussed above, while cytochrome $b_{6} f$ and the $\mathrm{NDH}$-like complexes appeared to accumulate (Supplementary Table 6), which is in accordance with the necessity to control electron flows during light fluctuation. In comparison, PSII abundance changed little as the photoprotective NPQ capacity increased to downregulate PSII activity in both young and mature leaves (Alter et al., 2012; Schneider et al., 2019). However, individual protein subunits of these large complexes showed highly specific changes in FL. For instance, psbH, a small one-helix phosphoprotein subunit of PSII reaction center which is required for accumulation of CP47 (Levey et al., 2014), showed a significant reduction $(50 \%-84 \%$ of the levels in CL) in protein abundance in nearly all samples (Table 2). Likewise, NDHM, a unique photosynthetic subunit of the NDH-like complex which may stabilize the conserved core component NDHK (Yamamoto et al., 2016), was consistently and significantly increased in FL $(+25 \%-35 \%)$, whereas the FL responses of other subunits were smaller and/or not significant except PNSB1 which increased by $\sim 10 \%$ from morning to the end of day in both young and mature leaves (Supplementary Table 6). These results suggest that acclimation may specifically modulate the abundance of subunits and enzymes which determine the assembly, stability, or activity of protein complexes (e.g., psbH, NDHM).

Protein synthesis and degradation constitutes a major resource allocation for the plant (Nelson and Millar, 2015; Li et al., 2017). This is reflected in markedly reduced rates of protein translation in the dark (Piques et al., 2009; Pal et al., 2013) and dependency of translation on carbon availability (Ishihara et al., 2015). Thus, transcriptional changes observed early in the morning (Schneider et al., 2019) may not yet be translated into changes in protein abundance in the same samples. This could provide an additional explanation for the much fewer changes in proteome observed in MY and MM compared to EY and EM (Figures 3 and 4).

Remarkably, FL predominantly upregulated transcription of various genes in all MY, MM, EY, and EM, with relatively few genes repressed in expression (Schneider et al., 2019). In contrast, the proportion of proteins with increased and reduced abundance was approximately equal (Figure 5A), indicating greater importance of post-transcriptional mechanisms for decreasing the abundance of individual proteins during acclimation. Furthermore, even for genes/ proteins found upregulated both on transcript and protein levels, the relationship between the changes in abundance of transcript and protein was specific for each gene/protein pair (Figure 5B), suggesting protein-specific fine-tuning. Most severely affected were nine mainly plastid-localized proteins, showing reduced abundance despite increased transcript levels 
in EM (Table 3). These included proteins involved in plastid translation (a putative bacterial trigger factor, threonyl-tRNA synthetase, and a $50 \mathrm{~S}$ ribosomal protein) and $\mathrm{CO}_{2}$ assimilation (RBCS1B, GAPA1). It is conceivable that the mild but chronic photooxidative conditions in our FL treatment trigger these changes in chloroplast proteins at the end of day, presumably by enhancing protein degradation and/or inhibiting translation.

To clarify the relative contributions of protein synthesis and degradation to the observed changes in the abundance of different proteins, future studies should aim to determine the rates of protein translation, e.g., by ribosome profiling (Juntawong et al., 2014; Mazzoni-Putman and Stepanova, 2018), and degradation, e.g., using metabolic stable isotope labeling ( $\mathrm{Li}$ et al., 2017), during acclimation to FL conditions.

\section{Towards a Systems-Level Understanding of Proteome Adjustment in FL Acclimation}

Previous studies have characterized changes in plant phenotype under FL conditions, including growth, photosynthetic performance, gene transcription, metabolome, and the abundance of selected proteins (Yin and Johnson, 2000; Alter et al., 2012; Huang et al., 2015; Kaiser et al., 2016; Vialet-Chabrand et al., 2017; Schneider et al., 2019). Our study now provides a first overview of dynamic acclimatory changes in the proteomes of Arabidopsis leaves during long-term acclimation to FL.

A still unknown factor in FL conditions is the extent of oxidative damage and protein modifications caused by excess light, excess electrons, and ROS. If FL intensifies these inhibitory effects, costs of damage and repair would increase in parallel with acute demand for protection and alternative pathways to mitigate the stress. The changes in leaf proteome and transcriptome observed in our FL conditions support this scenario. Concomitant upregulation of these and related processes will necessitate energy and resource, which, together with increased loss of light energy and fixed carbon by NPQ and photorespiration, would restrict the resource availability for growth. In fact, cell cycle- and growth-related genes were downregulated in young and mature leaves accumulating less starch, less sugars, and less amino acids under FL (Schneider et al., 2019).

To fully unravel the mechanisms of acclimatory proteome adjustments, it is necessary to overcome technical limitations. Here, we identified 2,313 proteins, but only 972 (or $42 \%$ ) of these were reliably quantified in all four samples. Due to the stochastic nature of mass spectrometry-based experiments, the absence of quantitative information does not mean the absence of the protein, which impaired comparison across samples. In future studies, this may be overcome by targeted and/or dataindependent mass spectrometry approaches that increase proteome coverage and precision of quantification (Navarro et al., 2016; Ludwig et al., 2018). Separate preparation of soluble and membrane protein fractions may further improve proteome coverage particularly of the latter fraction and reveal changes in physiologically important protein complexes and transporters in thylakoid membranes and chloroplast envelopes (Ferro et al., 2010). Furthermore, a variety of oxidative protein modifications, which may be triggered by photooxidative stress under FL to alter protein stability (Galetskiy et al., 2011) and enzymatic activities (Stroher and Dietz, 2008; Zaffagnini et al., 2012) or to mediate signaling (Noctor et al., 2018), may be identified by selective redox proteomics (Astier et al., 2011; Mock and Dietz, 2016). It is well known that such post-translational modifications can alter enzyme activity without changes in protein abundance.

\section{CONCLUDING REMARKS}

Long-term acclimation to FL involves both constitutive and dynamic adjustments of the proteome in young and mature leaves of Arabidopsis. Dynamic adjustments, mostly occurring during the daytime, may allow flexible and iterative responses to highly variable and unpredictable changes in natural light environments. Constitutive adjustments, on the other hand, are more rewarding when the condition is not changing substantially from day to day. While some major components of FL acclimation, such as upregulation of CEF and photorespiratory pathway, engage changes in both transcript and protein abundance, post-transcriptional regulation seems to modulate the relationship between these changes in a protein-specific manner. The mechanisms of proteome acclimation in FL await further investigations, including the analyses of translation and proteolysis or post-translational protein modifications.

\section{DATA AVAILABILITY STATEMENT}

The datasets generated for this study can be found in the PRIDE partner repository of the ProteomeXchange Consortium (https:// www.ebi.ac.uk/pride/archive/) with the following accession number: PXD015330.

\section{AUTHOR CONTRIBUTIONS}

$\mathrm{SN}$ and $\mathrm{M}-\mathrm{OB}$ performed shotgun proteomics experiments. TS performed the plant stress experiment and harvested material. $\mathrm{SN}, \mathrm{SM}$, and $\mathrm{PH}$ analyzed and interpreted the data and wrote the manuscript. SM and PH designed and supervised the project.

\section{FUNDING}

This work was in part supported by funding from the European Research Council under the European Union's Horizon 2020 research and innovation program (starting grant 639905 "ProPlantStress" to $\mathrm{PH}$ ) and by the Deutsche Forschungsgemeinschaft (IRTG1525 to $\mathrm{SM})$.

\section{SUPPLEMENTARY MATERIAL}

The Supplementary Material for this article can be found online at: https://www.frontiersin.org/articles/10.3389/fgene.2020. 00154/full\#supplementary-material 


\section{REFERENCES}

Altelaar, A. F., Frese, C. K., Preisinger, C., Hennrich, M. L., Schram, A. W., Timmers, H. T., et al. (2013). Benchmarking stable isotope labeling based quantitative proteomics. J. Proteomics 88, 14-26. doi: 10.1016/ j.jprot.2012.10.009

Alter, P., Dreissen, A., Luo, F. L., and Matsubara, S. (2012). Acclimatory responses of Arabidopsis to fluctuating light environment: comparison of different sunfleck regimes and accessions. Photosynth. Res. 113, 221-237. doi: 10.1007/s11120-012-9757-2

Anderson, J., Chow, W., and Goodchild, D. (1988). Thylakoid Membrane Organisation in Sun/Shade Acclimation. Funct. Plant Biol. 15, 11-26. doi: 10.1071/PP9880011

Anderson, J. M., Park, Y.-I., and Chow, W. S. (1997). Photoinactivation and photoprotection of photosystem II in nature. Physiol. Plant 100, 214-223. doi: 10.1111/j.1399-3054.1997.tb04777.x

Annunziata, M. G., Apelt, F., Carillo, P., Krause, U., Feil, R., Mengin, V., et al. (2017). Getting back to nature: a reality check for experiments in controlled environments. J. Exp. Bot. 68, 4463-4477. doi: 10.1093/jxb/erx220

Aro, E. M., McCaffery, S., and Anderson, J. M. (1993). Photoinhibition and D1 protein degradation in peas acclimated to different growth irradiances. Plant Physiol. 103, 835-843. doi: 10.1104/pp.103.3.835

Asada, K. (1999). THE WATER-WATER CYCLE IN CHLOROPLASTS: scavenging of active oxygens and dissipation of excess photons. Annu. Rev. Plant Physiol. Plant Mol. Biol. 50, 601-639. doi: 10.1146/annurev.arplant.50.1.601

Asensi-Fabado, M. A., and Munne-Bosch, S. (2010). Vitamins in plants: occurrence, biosynthesis and antioxidant function. Trends Plant Sci. 15, 582592. doi: 10.1016/j.tplants.2010.07.003

Astier, J., Rasul, S., Koen, E., Manzoor, H., Besson-Bard, A., Lamotte, O., et al. (2011). S-nitrosylation: an emerging post-translational protein modification in plants. Plant Sci. 181, 527-533. doi: 10.1016/j.plantsci.2011.02.011

Beck, S., Michalski, A., Raether, O., Lubeck, M., Kaspar, S., Goedecke, N., et al. (2015). The impact II, a very high-resolution quadrupole time-of-flight instrument (QTOF) for deep shotgun proteomics. Mol. Cell Proteomics 14, 2014-2029. doi: 10.1074/mcp.M114.047407

Blum, H., Beier, H., and Gross, H. J. (1987). Improved silver staining of plant proteins, RNA and DNA in polyacrylamide gels. Electrophoresis 8, 93-99. doi: 10.1002/elps.1150080203

Boersema, P. J., Raijmakers, R., Lemeer, S., Mohammed, S., and Heck, A. J. (2009). Multiplex peptide stable isotope dimethyl labeling for quantitative proteomics. Nat. Protoc. 4, 484-494. doi: 10.1038/nprot.2009.21

Casano, L. M., Martin, M., and Sabater, B. (2001). Hydrogen peroxide mediates the induction of chloroplastic Ndh complex under photooxidative stress in Barley. Plant Physiol. 125, 1450-1458. doi: 10.1104/pp.125.3.1450

Cox, J., and Mann, M. (2008). MaxQuant enables high peptide identification rates, individualized p.p.b.-range mass accuracies and proteome-wide protein quantification. Nat. Biotechnol. 26, 1367-1372. doi: 10.1038/nbt.1511

De Souza, A. P., Wang, Y., Orr, D. J., Carmo-Silva, E., and Long, S. P. (2020). Photosynthesis across African cassava germplasm is limited by Rubisco and mesophyll conductance at steady-state, but by stomatal conductance in fluctuating light. New Phytol. 225, 2498-2512. doi: 10.1111/nph.16142

Demir, F., Niedermaier, S., Kizhakkedathu, J. N., and Huesgen, P. F. (2017). Profiling of protein N-Termini and their modifications in complex samples. Methods Mol. Biol. 1574, 35-50. doi: 10.1007/978-1-4939-6850-3_4

Demmig-Adams, B. (1998). Survey of thermal energy dissipation and pigment composition in sun and shade leaves. Plant Cell Physiol. 39, 474-482. doi: 10.1093/oxfordjournals.pcp.a029394

Deutsch, E. W., Csordas, A., Sun, Z., Jarnuczak, A., Perez-Riverol, Y., Ternent, T., et al. (2017). The ProteomeXchange consortium in 2017: supporting the cultural change in proteomics public data deposition. Nucleic Acids Res. 45, D1100-D1106. doi: 10.1093/nar/gkw936

Dietz, K. J. (2015). Efficient high light acclimation involves rapid processes at multiple mechanistic levels. J. Exp. Bot. 66, 2401-2414. doi: 10.1093/jxb/eru505

Ferro, M., Brugiere, S., Salvi, D., Seigneurin-Berny, D., Court, M., Moyet, L., et al. (2010). AT_CHLORO, a comprehensive chloroplast proteome database with subplastidial localization and curated information on envelope proteins. Mol. Cell Proteomics 9, 1063-1084. doi: 10.1074/mcp.M900325-MCP200
Franklin, K. A. (2008). Shade avoidance. New Phytol. 179, 930-944. doi: 10.1111/ j.1469-8137.2008.02507.x

Galetskiy, D., Lohscheider, J. N., Kononikhin, A. S., Popov, I. A., Nikolaev, E. N., and Adamska, I. (2011). Mass spectrometric characterization of photooxidative protein modifications in Arabidopsis thaliana thylakoid membranes. Rapid Commun. Mass Spectrom. 25, 184-190. doi: 10.1002/rcm.4855

Grace, S. C., and Logan, B. A. (1996). Acclimation of Foliar antioxidant systems to growth irradiance in three broad-leaved evergreen species. Plant Physiol. 112, 1631-1640. doi: 10.1104/pp.112.4.1631

Hager, A., and Holocher, K. (1994). Localization of the xanthophyll-cycle enzyme violaxanthin de-epoxidase within the thylakoid lumen and abolition of its mobility by a (light-dependent) $\mathrm{pH}$ decrease. Planta 192, 581-589. doi: 10.1007/BF00203597

Huang, W., Hu, H., and Zhang, S. B. (2015). Photorespiration plays an important role in the regulation of photosynthetic electron flow under fluctuating light in tobacco plants grown under full sunlight. Front. Plant Sci. 6, 621. doi: 10.3389/ fpls.2015.00621

Hunt, L., Amsbury, S., Baillie, A., Movahedi, M., Mitchell, A., Afsharinafar, M. et al. (2017). Formation of the stomatal outer cuticular ledge requires a guard cell wall proline-rich protein. Plant Physiol. 174, 689-699. doi: 10.1104/ pp. 16.01715

Ishihara, H., Obata, T., Sulpice, R., Fernie, A. R., and Stitt, M. (2015). Quantifying protein synthesis and degradation in Arabidopsis by dynamic 13CO2 labeling and analysis of enrichment in individual amino acids in their free pools and in protein. Plant Physiol. 168, 74-93. doi: 10.1104/pp.15.00209

Jarvi, S., Suorsa, M., and Aro, E. M. (2015). Photosystem II repair in plant chloroplasts-regulation, assisting proteins and shared components with photosystem II biogenesis. Biochim. Biophys. Acta 1847, 900-909. doi: 10.1016/j.bbabio.2015.01.006

Juntawong, P., Girke, T., Bazin, J., and Bailey-Serres, J. (2014). Translational dynamics revealed by genome-wide profiling of ribosome footprints in Arabidopsis. Proc. Natl. Acad. Sci. U. S. A 111, E203-E212. doi: 10.1073/ pnas.1317811111

Kaiser, E., Morales, A., Harbinson, J., Heuvelink, E., Prinzenberg, A. E., and Marcelis, L. F. (2016). Metabolic and diffusional limitations of photosynthesis in fluctuating irradiance in Arabidopsis thaliana. Sci. Rep. 6, 31252. doi: $10.1038 /$ srep31252

Kaiser, E., Morales, A., and Harbinson, J. (2018). Fluctuating light takes crop photosynthesis on a rollercoaster ride. Plant Physiol. 176, 977-989. doi: 10.1104/pp.17.01250

Kono, M., Yamori, W., Suzuki, Y., and Terashima, I. (2017). Photoprotection of PSI by far-red light against the fluctuating light-induced photoinhibition in Arabidopsis thaliana and field-grown plants. Plant Cell Physiol. 58, 35-45. doi: $10.1093 / \mathrm{pcp} / \mathrm{pcw} 215$

Laemmli, U. K. (1970). Cleavage of structural proteins during the assembly of the head of bacteriophage T4. Nature 227, 680-685. doi: 10.1038/227680a0

Levey, T., Westhoff, P., and Meierhoff, K. (2014). Expression of a nuclear-encoded psbH gene complements the plastidic RNA processing defect in the PSII mutant hcf107 in Arabidopsis thaliana. Plant J. 80, 292-304. doi: 10.1111/ tpj. 12632

Li, X. P., Gilmore, A. M., Caffarri, S., Bassi, R., Golan, T., Kramer, D., et al. (2004). Regulation of photosynthetic light harvesting involves intrathylakoid lumen pH sensing by the PsbS protein. J. Biol. Chem. 279, 22866-22874. doi: 10.1074/ jbc.M402461200

Li, L., Nelson, C. J., Trosch, J., Castleden, I., Huang, S., and Millar, A. H. (2017) Protein degradation rate in arabidopsis thaliana leaf growth and development. Plant Cell. 29, 207-228. doi: 10.1105/tpc.1116.00768

Li, L., Aro, E. M., and Millar, A. H. (2018). Mechanisms of photodamage and protein turnover in photoinhibition. Trends Plant Sci. 23, 667-676. doi: 10.1016/j.tplants.2018.05.004

Ludwig, C., Gillet, L., Rosenberger, G., Amon, S., Collins, B. C., and Aebersold, R. (2018). Data-independent acquisition-based SWATH-MS for quantitative proteomics: a tutorial. Mol. Syst. Biol. 14, e8126. doi: 10.15252/msb.20178126

Martín, M., Casano, L. M., and Sabater, B. (1996). Identification of the product of ndhA gene as a Thylakoid protein synthesized in response to photooxidative treatment. Plant Cell Physiol. 37, 293-298. doi: 10.1093/oxfordjournals. pcp.a028945 
Matsubara, S. (2018). Growing plants in fluctuating environments: why bother? J. Exp. Bot. 69, 4651-4654. doi: 10.1093/jxb/ery312

Mazzoni-Putman, S. M., and Stepanova, A. N. (2018). A plant biologist's toolbox to study translation. Front. Plant Sci. 9, 873. doi: 10.3389/fpls.2018.00873

Mock, H. P., and Dietz, K. J. (2016). Redox proteomics for the assessment of redox-related posttranslational regulation in plants. Biochim. Biophys. Acta 1864, 967-973. doi: 10.1016/j.bbapap.2016.01.005

Munekage, Y., Hojo, M., Meurer, J., Endo, T., Tasaka, M., and Shikanai, T. (2002). PGR5 is involved in cyclic electron flow around photosystem I and Is essential for photoprotection in Arabidopsis. Cell 110, 361-371. doi: 10.1016/S00928674(02)00867-X

Navarro, P., Kuharev, J., Gillet, L. C., Bernhardt, O. M., MacLean, B., Rost, H. L., et al. (2016). A multicenter study benchmarks software tools for label-free proteome quantification. Nat. Biotechnol. 34, 1130-1136. doi: 10.1038/nbt.3685

Nelson, C. J., and Millar, A. H. (2015). Protein turnover in plant biology. Nat. Plants 1, 15017. doi: 10.1038/nplants.2015.17

Nishiyama, Y., Allakhverdiev, S. I., Yamamoto, H., Hayashi, H., and Murata, N. (2004). Singlet oxygen inhibits the repair of photosystem II by suppressing the translation elongation of the D1 protein in synechocystis sp PCC 6803. Biochemistry 2004, 11321-11330. doi: 10.1021/bi036178q

Noctor, G., and Foyer, C. H. (1998). ASCORBATE AND GLUTATHIONE: keeping active oxygen under control. Annu. Rev. Plant Physiol. Plant Mol. Biol. 49, 249-279. doi: 10.1146/annurev.arplant.49.1.249

Noctor, G., Reichheld, J. P., and Foyer, C. H. (2018). ROS-related redox regulation and signaling in plants. Semin. Cell Dev. Biol. 80, 3-12. doi: 10.1016/ j.semcdb.2017.07.013

Oelze, M.-L., Muthuramalingam, M., Vogel, M. O., and Dietz, K.-J. (2014). The link between transcript regulation and de novo protein synthesis in the retrograde high light acclimation response of Arabidopsis thaliana. BMC Genomics 15, 1- 14. doi: 10.1186/1471-2164-15-320

Ort, D. R., Merchant, S. S., Alric, J., Barkan, A., Blankenship, R. E., Bock, R., et al. (2015). Redesigning photosynthesis to sustainably meet global food and bioenergy demand. Proc. Natl. Acad. Sci. U. S. A 112, 8529-8536. doi: 10.1073/pnas.1424031112

Pal, S. K., Liput, M., Piques, M., Ishihara, H., Obata, T., Martins, M. C., et al. (2013). Diurnal changes of polysome loading track sucrose content in the rosette of wild-type arabidopsis and the starchless pgm mutant. Plant Physiol. 162, 1246-1265. doi: 10.1104/pp.112.212258

Perez-Riverol, Y., Csordas, A., Bai, J., Bernal-Llinares, M., Hewapathirana, S., Kundu, D. J., et al. (2019). The PRIDE database and related tools and resources in 2019: improving support for quantification data. Nucleic Acids Res. 47, D442-D450. doi: 10.1093/nar/gky1106

Phipson, B., Lee, S., Majewski, I. J., Alexander, W. S., and Smyth, G. K. (2016). Robust hyperparameter estimation protects against hypervariable genes and improves power to detect differential expression. Ann. Appl. Stat. 10, 946-963. doi: 10.1214/16-AOAS920

Piques, M., Schulze, W. X., Hohne, M., Usadel, B., Gibon, Y., Rohwer, J., et al. (2009). Ribosome and transcript copy numbers, polysome occupancy and enzyme dynamics in Arabidopsis. Mol. Syst. Biol. 5, 314. doi: 10.1038/msb.2009.68

Poorter, H., Niinemets, U., Ntagkas, N., Siebenkas, A., Maenpaa, M., Matsubara, S., et al. (2019). A meta-analysis of plant responses to light intensity for 70 traits ranging from molecules to whole plant performance. New Phytol. 223, 1073-1105. doi: 10.1111/nph.15754

Rappsilber, J., Mann, M., and Ishihama, Y. (2007). Protocol for micro-purification, enrichment, pre-fractionation and storage of peptides for proteomics using StageTips. Nat. Protoc. 2, 1896-1906. doi: 10.1038/nprot.2007.261

Raudvere, U., Kolberg, L., Kuzmin, I., Arak, T., Adler, P., Peterson, H., et al. (2019). g:Profiler: a web server for functional enrichment analysis and conversions of gene lists, (2019 update). Nucleic Acids Res. 47, W191-W198. doi: 10.1093/nar/gkz369

Ritchie, M. E., Phipson, B., Wu, D., Hu, Y., Law, C. W., Shi, W., et al. (2015). limma powers differential expression analyses for RNA-sequencing and microarray studies. Nucleic Acids Res. 43, e47. doi: 10.1093/nar/gkv007
Schneider, T., Bolger, A., Zeier, J., Preiskowski, S., Benes, V., Trenkamp, S., et al. (2019). Fluctuating light interacts with time of day and leaf development stage to reprogram gene expression. Plant Physiol. 179, 1632-1657. doi: 10.1104/ pp. 18.01443

Schottler, M. A., and Toth, S. Z. (2014). Photosynthetic complex stoichiometry dynamics in higher plants: environmental acclimation and photosynthetic flux control. Front. Plant Sci. 5, 188. doi: 10.3389/fpls.2014.00188

Shikanai, T., Endo, T., Hashimoto, T., Yamada, Y., Asada, K., and Yokota, A. (1998). Directed disruption of the tobacco ndhB gene impairs cyclic electron flow around photosystem I. Proc. Natl. Acad. Sci. U. S. A 95, 9705-9709. doi: 10.1073/pnas.95.16.9705

Stroher, E., and Dietz, K. J. (2008). The dynamic thiol-disulphide redox proteome of the Arabidopsis thaliana chloroplast as revealed by differential electrophoretic mobility. Physiol. Plant 133, 566-583. doi: 10.1111/j.13993054.2008.01103.x

Takizawa, K., Cruz, J. A., Kanazawa, A., and Kramer, D. M. (2007). The thylakoid proton motive force in vivo. Quantitative, non-invasive probes, energetics, and regulatory consequences of light-induced pmf. Biochim. Biophys. Acta 1767, 1233-1244. doi: 10.1016/j.bbabio.2007.07.006

Theis, J., and Schroda, M. (2016). Revisiting the photosystem II repair cycle. Plant Signal Behav. 11, e1218587. doi: 10.1080/15592324.2016.1218587

Tikkanen, M., Grieco, M., Nurmi, M., Rantala, M., Suorsa, M., and Aro, E. M. (2012). Regulation of the photosynthetic apparatus under fluctuating growth light. Philos. Trans. R. Soc. Lond. B. Biol. Sci. 367, 3486-3493. doi: 10.1098/ rstb.2012.0067

Tyanova, S., and Cox, J. (2018). Perseus: a bioinformatics platform for integrative analysis of proteomics data in cancer research. Methods Mol. Biol. 1711, 133148. doi: 10.1007/978-1-4939-7493-1_7

Vialet-Chabrand, S., Matthews, J. S., Simkin, A. J., Raines, C. A., and Lawson, T. (2017). Importance of fluctuations in light on plant photosynthetic acclimation. Plant Physiol. 173, 2163-2179. doi: 10.1104/pp.16.01767

Walters, R. G. (2005). Towards an understanding of photosynthetic acclimation. J. Exp. Bot. 56, 435-447. doi: 10.1093/jxb/eri060

Weng, S. S. H., Demir, F., Ergin, E. K., Dirnberger, S., Uzozie, A., Tuscher, D., et al. (2019). Sensitive determination of proteolytic proteoforms in limited microscale proteome samples. Mol. Cell Proteomics. 18, 2335-2347. doi: 10.1074/mcp.TIR119.001560

Wessel, D., and Flügge, U. I. (1984). A method for the quantitative recovery of protein in dilute solution in the presence of detergents and lipids. Anal. Biochem. 138, 141-143. doi: 10.1016/0003-2697(84)90782-6

Yamamoto, H., Fan, X., Sugimoto, K., Fukao, Y., Peng, L., and Shikanai, T. (2016). CHLORORESPIRATORY REDUCTION 9 is a novel factor required for formation of subcomplex a of the Chloroplast NADH Dehydrogenase-Like Complex. Plant Cell Physiol. 57, 2122-2132. doi: 10.1093/pcp/pcw130

Yin, Z. H., and Johnson, G. N. (2000). Photosynthetic acclimation of higher plants to growth in fluctuating light environments. Photosynth. Res. 63, 97-107. doi: 10.1023/A:1006303611365

Zaffagnini, M., Bedhomme, M., Lemaire, S. D., and Trost, P. (2012). The emerging roles of protein glutathionylation in chloroplasts. Plant Sci. 185-186, 86-96. doi: 10.1016/j.plantsci.2012.01.005

Conflict of Interest: The authors declare that the research was conducted in the absence of any commercial or financial relationships that could be construed as a potential conflict of interest.

Copyright $\odot 2020$ Niedermaier, Schneider, Bahl, Matsubara and Huesgen. This is an open-access article distributed under the terms of the Creative Commons Attribution License (CC BY). The use, distribution or reproduction in other forums is permitted, provided the original author(s) and the copyright owner(s) are credited and that the original publication in this journal is cited, in accordance with accepted academic practice. No use, distribution or reproduction is permitted which does not comply with these terms. 